\title{
WestVirginiaUniversity
}

THE RESEARCH REPOSITORY @ WVU

Graduate Theses, Dissertations, and Problem Reports

2004

\section{Exposures to silica and inducers of xenobiotic metabolism in the rat lung}

Lori A. Battelli

West Virginia University

Follow this and additional works at: https://researchrepository.wvu.edu/etd

\section{Recommended Citation}

Battelli, Lori A., "Exposures to silica and inducers of xenobiotic metabolism in the rat lung" (2004). Graduate Theses, Dissertations, and Problem Reports. 2063.

https://researchrepository.wvu.edu/etd/2063

This Thesis is protected by copyright and/or related rights. It has been brought to you by the The Research Repository @ WVU with permission from the rights-holder(s). You are free to use this Thesis in any way that is permitted by the copyright and related rights legislation that applies to your use. For other uses you must obtain permission from the rights-holder(s) directly, unless additional rights are indicated by a Creative Commons license in the record and/ or on the work itself. This Thesis has been accepted for inclusion in WVU Graduate Theses, Dissertations, and Problem Reports collection by an authorized administrator of The Research Repository @ WVU. For more information, please contact researchrepository@mail.wvu.edu. 
Exposures to Silica and Inducers of Xenobiotic

Metabolism in the Rat Lung

\author{
Lori A. Battelli
}

Thesis submitted to the

Davis College of Agriculture, Forestry, and Consumer Sciences

at West Virginia University in partial fulfillment

for the degree of

\title{
Master of Science
}

in

Genetics and Developmental Biology Program

Ann Hubbs, Ph.D. Chair

Joginder Nath, Ph.D. Co-Chair

Sharon Wenger, Ph.D.

Morgantown, WV

2004

Keywords: Cytochrome P4501A1, polycyclic aromatic hydrocarbons, respirable particles, silica, epidemiology 


\title{
ABSTRACT \\ EXPOSURES TO SILICA AND INDUCERS OF XENOBIOTIC METABOLISM IN THE RAT LUNG
}

\begin{abstract}
Lori A. Battelli
CYP1A1 metabolizes polycyclic aromatic hydrocarbons (PAHs), such as those in cigarettes, to reactive intermediates which interact with DNA and lead to cancer. Silica is a lung carcinogen. Epidemiology studies of silica and lung cancer are not all positive. A possible explanation for these inconsistencies may be that silica is a modifier of PAH metabolism and, thus, cigarette smoke carcinogenesis. We hypothesize that crystalline silica exposure alters CYP1A1 expression, thereby modifying lung cancer risk.

Rats exposed to both crystalline silica and the model PAH, $\beta$-naphthoflavone (NF), a CYP1A1 inducer have significantly decreased CYP1A1 enzymatic activity and CYP1A1 protein expression. In the proximal alveolar region of NF- exposed rats, silica exposure increases markers of alveolar type II cells but decreases proportional CYP1A1 expression in type II cells as detected by immunofluorescence. Our experiments support the hypothesis that silica is a negative modifier of CYP1A1 induction by PAH.
\end{abstract}




\section{ACKNOWLEDGEMENTS}

I must first express my gratefulness for the continuous moral support and guidance from Dr. Ann Hubbs. I also thank Dr. Joginder Nath and Dr. Sharon Wenger for participating on my committee and providing valuable insight.

There are many people at NIOSH that I am grateful for their help and support: Mark Barger, for assisting in IT instillations, lung micrososme preparation, and Western Blot technique.

Mike Kashon for statistical analysis, Mike Whitmer and Dan Lewis for endotoxin analysis, and Val Vallyathan for providing silica particles and analysis data.

The PPRB histology lab for preparing the microscope slides. Patsy Willard for her valuable advice on IHC and IF staining and Lyndell Millecchea for photomicroscopy and imaging support.

Dr. Mohamed Ghanem for advice, support and help in conducting experiments.

There are also many friends and family members I must also thank for their encouragement and support of my graduate work. 
Abstract

ii

Acknowledgements

Table of Contents

List of Tables

List of Figures

List of Symbols

Chapter 1

Introduction

Objectives

iii

iv

$\mathrm{v}$

vi

vii

$1-5$

Chapter 2 Review of Literature

5

1 - Cytochrome P450 (CYP)

$6-22$

2 - Cytochrome P4501A1 (CYP1A1)

3 - CYP1A1 and Carcinogenesis

4 - CYP1A1 and Polymorphisms 14

5 - Lung Physiology

6 - Crystalline Silica

Chapter 3 Material and Methods

Chapter 4 Results

Chapter 5 Discussion

Conclusion

Bibliography

9

12

16

18

6

4

$23-43$

$44-57$

$58-62$

63

64 - 70

71 
M1 Experimental Design for Experiment 1 25

M2 Experimental Design for Experiment 2 26

M3 Experimental Design for Experiment 3 27

M4 Histopathology Scoring Table 34

R1 Pathology Scores for Experiment 3 44 
List of Figures vi vi

1. Phase I and Phase II Reaction Pathway 7

2. Biotransformation of Xenobiotics 8

3. CYP1A1 Induction 11

4. CYP1A1 Catalyzed Reaction 12

5. Metabolic Activation to Carcinogenesis 13

6. Lung Physiology - Alveolar region 16

7. Lung Physiology - Terminal Bronchiole/Clara Cells 17

8. Proximal Alveolar Region 42

9. Random Alveolar Region 42

10. Double IF staining 42

11. Example of silicotic lung 45

12. CYP2B1 IHC (Exp 1) 46

13. CYP1A1 IHC (Exp 1) 47

14. EROD and ECOD (Exp 1) 48

15. CYP1A1/CYTO 8 IF Proximal Alveolar Regions (Exp 2) 50

16. Proximal Alveolar Region graphs 51

17. CYP1A1/CYTO 8 IF Random Alveolar Regions (Exp 2) 52

18. Random Alveolar Region graphs 53

19. $\quad$ EROD/PROD (Exp 2) 54

20. CYP1A1 Western (Exp 2) 54

21. $\quad$ EROD/PROD (Exp 3) 55

22. CYP1A1 and CYP2B1 Western (Exp 3) 56

23. Western Graph (Exp 3) 57 


\begin{tabular}{ll} 
Ahr & Aryl hydrocarbon receptor \\
AIP & Aryl hydrocarbon receptor interacting protein \\
AM & Alveolar macrophage \\
Arnt & Aryl hydrocarbon receptor nuclear translocator \\
BALF & Bronchoalveolar lavage fluid \\
BCA & Bicinchoninic Acid \\
Bhlh & Basic helix loop helix \\
BSA & Bovine serum albumin \\
CYP & Cytochrome P450 \\
CYP1A1 & Cytochrome P4501A1 \\
CYP2B1 & Cytochrome P4502B1 \\
EDTA & Ethylenediamine tetracetate \\
ECOD & 7-Ethoxycoumarin-O-deethylase \\
EROD & 7-Ethoxyresorufin-O-deethylase \\
H \& E & Hematoxylin and Eosin \\
HRP & Horse radish peroxidase \\
IF & Immunofluorescence \\
IHC & Immunohistochemistry \\
IgG & Immunoglobulin G \\
IARC & International Agency for Research on Cancer \\
IP & Intraperitoneal \\
IT & Intratracheal \\
NADPH & Nicotinamide adenine dinucleotide phosphate \\
NBF & Neutral buffered formalin \\
NF & B-naphthoflavone \\
NFKB & Nuclear Factor Kappa B \\
PAH & Polycyclic aromatic hydrocarbon \\
PAS & Pers-arnt-sim \\
PBS & Phosphate Buffered Saline \\
PROD & 7-Pentoxyresorufin-O-deethylase \\
SDS & Sodium dodecyl sulphate \\
TBS & Tris Buffered saline \\
TNFa & Tumor necrosis factor alpha \\
XRE & Xenobiotic response element \\
& \\
\hline
\end{tabular}




\section{Chapter 1}

\section{Introduction}

Cytochrome P450s (CYPS) have been shown to play a key role in activating procarcinogens. Cytochrome P4501A1 (CYP1A1) is responsible for the metabolism of polycyclic aromatic hydrocarbons (PAHs), such as those found in tobacco byproducts. In the early 1970s, cultured lymphocytes showed a link between high AHH (aryl hydrocarbon hydroxylase) activity and increased risk of lung cancer (Kellerman et al, 1973). CYP1A1 is an important enzyme involved in lung cancer initiation because it activates PAHs and is responsible for the expression of the AHH activity (Bartsch et al 1992; Bartsch et al,1999; Kellerman et al, 1973). Experiments have shown that during CYP1A1 metabolism, PAHs are epoxidized, then hydrolyzed by epoxide hydrolase to a dihydrodiol and ultimately oxidized to the diolepoxide or ultimate carcinogen (Hasler et $a l, 1999)$. These diolepoxides are highly reactive and can form DNA adducts leading to mutations and possibly activating oncogenes or tumor suppressor genes (Kondraganti, et $a l, 2002)$.

Humans are continuously exposed to a variety of foreign compounds via lung inhalation. These exposures can lead to alterations in the lung metabolism or cause cellular injury, or both. Workers in both mining and non-mining (masonry, pottery, sand blasting) professions can be exposed to respirable silica. Exposures to respirable silica can be both chronic and acute and can lead to silicosis, and related diseases such as silicotuberculosis, and scleroderma. Although there have been inconsistencies noted in data associating risk of lung cancer and exposure to respirable silica, the International Agency for Research on Cancer (IARC) classified silica as a carcinogen in 1997. Cocco 
et al (2001) found an association between lung cancer and silica exposure that surprisingly was stronger in workers exposed to silica than workers exposed to both silica and PAHs. PAHs, such as those found in cigarette smoke are known to increase the risk of developing cancer. Knowing that both silica exposure and PAH exposure alone can increase lung cancer risk one might expect an additive effect when co-exposed. However, if silica modifies the carcinogenicity of the PAHs, these two lung carcinogens are not simple co-variables in causing lung cancers, but instead represent a complex risk. Experiments by Miles et al $(1993 ; 1994)$ and Levy et al (1997) investigated the possible link between silicosis and lung cancer and more specifically, the possible role of the pulmonary microsomal cytochrome P450 system in the initiation of lung cancer. In both studies, rats were intratracheally exposed to silica dust. Miles et al showed that the pulmonary microsomal CYP system was altered by intratracheal silica exposure resulting in increased activity levels of both CYP2B1 and CYP1A1 (Miles et al, 1993; Miles et al, 1994). Immunohistochemical (IHC) staining in lung tissues was negative for CYP1A1 expression in any cells. CYP2B1 was found in Clara cells and alveolar type II cells, but was not significantly different between groups (Levy et al,1997).

It is important to note that those experiments were done in lung that did not have CYP1A1 induced by PAH exposure. Immunohistochemical experiments by Levy et al (1997) showed that the increase in CYP activity was not due to the proliferation of type II cells of silicosis. In addition, the major known effect of CYP1A1 is on the metabolism of PAHs. Since PAHs both induce and are metabolized by CYP1A1, the effect of silica on CYP1A1 is most important where there are also exposures to PAHs. 
Based on those previous experiments, our experiments involve the use of CYP inducers and IT silica exposure. In the first experiment, we hypothesized that the new type II cells of silicosis were a potential site for CYP1A1 induction in the rat lung. Rats were exposed to silica and inducers of CYP - $\beta$-naphthoflavone, a CYP1A1 inducer; phenobarbital, a CYP2B1 inducer; or a combination of both. Endpoints measured included IHC for both CYP1A1 and CYP-dependent xenobiotic activity (7ethoxyresorufin-O-deethylase (EROD) and 7-ethoxycoumarin-O-deethylase (ECOD) respectively).

Based on results from the first experiment, we found it necessary to use immunofluorescence (IF), more specifically dual immunofluorescence to further determine the location of CYP1A1 in the lung. IF was selected because it is more sensitive than enzymatic IHC and easily allows for double labeling the tissue for 2 different proteins. Images were digitally captured and changes quantified by morphometric analysis. The sites of CYP isoform localization were determined by measuring colocalization of a CYP1A1 fluorescent probe with a marker of a specific cell type. In addition, the total area of the lung involved in CYP1A1 expression were measured by use of these fluorescent probes and the percent of that area of expression localized to alveolar type II cells was calculated from the co-localization of CYP1A1 and cytokeratin 8, an alveolar type II cell marker. Again, rats were exposed to silica and the CYP1A1 inducer $\beta$-naphthoflavone. Endpoints included IF for CYP1A1 and cytokeratin 8, Western blot for CYP1A1, CYP1A1-dependent activity (EROD) and CYP2B1 dependent activity (7-pentoxyresorufin-O-deethylase (PROD)). 
We also examined the hypothesis that the reduction of CYP1A1 activity by silica exposure was dose responsive, i.e., does this effect occur at low exposures and increase with increasing exposures. All animals were induced with NF and IT exposed to 5, 10 or 20 milligrams of silica. Endpoints measured included CYP1A1 dependent activity (EROD), CYP2B1 dependent activity (PROD), and Western blots for both CYP1A1 and CYP2B1. 
Objectives

Study objectives:

1. Determine the relationship between co-exposure to respirable silica dust and PAHs and CYP1A1 expression.

2. Determine the relationship between silicotic histopathologic

lung changes and the pattern of CYP1A1 expression in alveolar epithelial cells. 


\section{Chapter 2}

\section{Review of Literature}

\section{1 - Cytochrome P450 (CYPs)}

Cytochrome P4501A1 is a part of the Cytochrome P450 superfamily. CYPs are hemoproteins that are part of an enzyme system that help mediate xenobiotic metabolism.

In the late 1950s, Klingenberg discovered this unique protein that was known as “microsomal carbon monoxide-binding pigment” (Omura, 1999; Estabrook, 1998).

Omura and Sato discovered the hemoprotein nature of this pigment and proposed the name Cytochrome P450 due to its maximum optical absorption peak of $450 \mathrm{~nm}$ (Omura, 1999; Estabrook, 1998). In this same time period (early 1960s) Hashimoto, Yamano, and Mason discovered what they thought was a new compound in liver microsomes. It turned out to be identical to Cytochrome P450 (Omura, 1999). The exact nature and function of this hemoprotein was discovered in 1963. Estabrook, Cooper, and Rosenthal were able to confirm that Cytochrome P450 was involved in hydroxylation reactions in 1963 (Omura, 1999). More experiments followed and Cytochrome P450 was found to be a mixed function oxidase, providing molecular oxygen to these reactions.

The body is constantly exposed to foreign compounds and the majority of these compounds are metabolized through the cytochrome P450 system (Philpot and Smith, 1984). There are two phases to these reactions, and CYPs participate in Phase I reactions. 
PHASE I

(Add functional groups)
PHASE II

(Biosynthetic Conjugation)

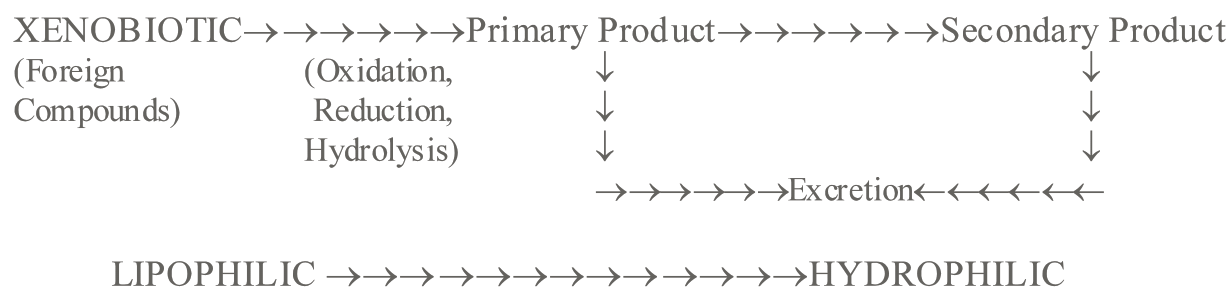

Figure 1. Phase I and Phase II Pathways. Figure adapted from Timbrell, J.A., 1993 Biotransfromation of Xenobiotics. General and Applied Toxicology Vol 1, (B. Ballantyne, T. Marrs, and P. Turner Eds.) Macmillan Publishing Co. New York, pp 89 116.

Phase I reactions include hydrolysis, reductions, and oxidations of foreign

compounds. During Phase I reactions, a functional group is added, making the compound slightly more water soluble and reactive. Phase II reactions which include glucouronidations, sulfonations, acetylations and methylations conjugate the phase I metabolite, usually resulting in a large increase in water solubility and excretability by the compound. The phase I metabolite is not stable, and can become reactive and lead to possible DNA damage. Instead of detoxifying the xenobiotic compound, the opposite can occur with a resulting toxicity increase. 


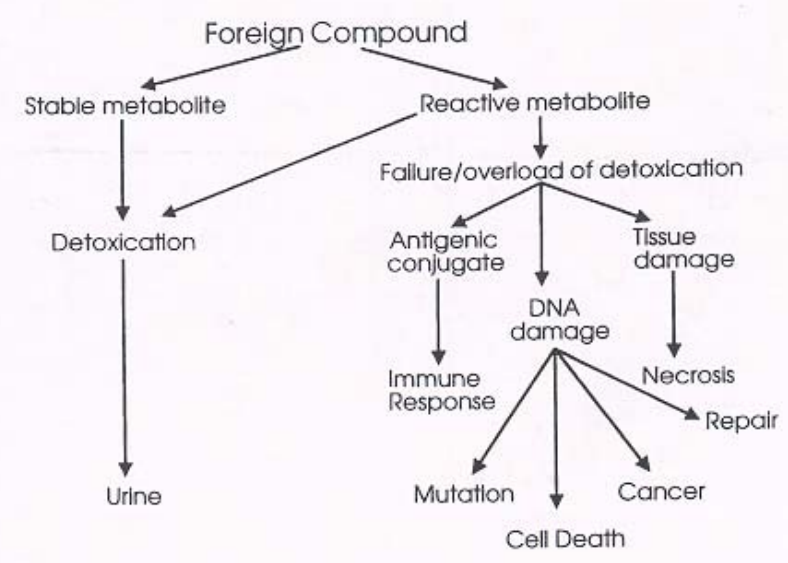

Figure 2. Biotransfromation of Xenobiotics. Adapted from Timbrell, J.A., 1993 General and Applied Toxicology Vol 1, (B. Ballantyne, T. Marrs, and P. Turner Eds.) Macmillan Publishing Co. New York, pp 89-116.

Genome projects have helped established that CYPs arose from a single ancestral form. Although the molecular species may be different, there are several conserved AA sequences found amongst all CYPs (Omura, 1999). Some prokaryotes and all animals, plants, fungi and eukaryotic organisms have CYPs. CYPs are found in the endoplasmic reticulum and can be species and tissue specific. Their expression can be sex and developmentally regulated. CYPs have been found to be involved in a variety of functions including the biosynthesis and metabolism of steroid hormones and the metabolism of various lipid biofactors such as eicosanoids, vitamin D3 and retinoids (Omura, 1999).

Close to a thousand CYP isoforms have been found. A nomenclature has been established placing the isoforms into families and subfamilies (Omiecinski et al, 1999). 
CYP - for Cytochrome P450

\# - for family (if the same number is used, this indicates greater than $40 \%$ protein sequence homology)

Letter - for subfamily (CYPs are in the same subfamily if they have greater than 55\% homology in the protein sequence)

\# - for gene

For example, the CYP1 family is the family using the aryl hydrocarbon receptor pathway.

There are 2 subfamilies, CYP1A and CYP1B. The CYP1A1 subfamily is made up of 2

genes, CYP1A1 which predominantly uses polycyclic aromatic hydrocarbons as substrates and CYP1A2 which predominantly uses aromatic amines as substrates.

CYP1B1 predominantly uses heterocyclic amines as substrates (Omiecinski et al, 1999).

Some CYPs are constitutively expressed and others are only expressed after induction.

Expression varies by species and tissue also.

\section{$\underline{2}$ - Cytochrome P4501A1 (CYP1A1)}

CYP1A1 is an inducible isoform and is involved in the metabolism of polycyclic aromatic hydrocarbons (PAHs). PAHs are common in combustion products, including cigarette smoke. CYP1A1 has been found in many tissues, including liver, lung, and brain. Expression is usually only detectable after induction and varies between tissues. 
Inducers of CYP1A1 are its substrates, the PAHs, which are present in cigarette smoke, charcoaled meat, soot and other common environmental contaminants. Examples include 3-methylcholanthrene (3-MC), $\beta$-naphthoflavone (NF), and dioxin (TCDD). Induction can cause an imbalance in detoxification and activation (Whitlock, 1999; Whitlock et al 1996).

PAHs induce their own metabolism; they are the substrate of CYP metabolism. They are found almost everywhere in the environment and one can easily be exposed via inhalation, intestinal absorption through eating and drinking, or through skin absorbance. PAHs are then metabolized by CYP1A1, with subsequent involvement of phase II metabolism.

Induction of CYP1A1 by an inducer causes an increase in the transcription of the gene, leading to increased Phase I products, DNA adducts, and somatic mutations, which could then possibly lead to carcinogenesis (Mucci et al, 2001).

There are several regulatory proteins involved in CYP1A1 induction. The AhR (aromatic hydrocarbon receptor) and ARNT (aromatic hydrocarbon receptor nuclear translocator) both pre-exist in cells, making induction of CYP1A1 a primary response associated with protein synthesis. Both AhR and ARNT are bHLH/PAS proteins (basic helix loop helix/pers-arnt-sim) that are involved in the regulation and maintenance of basic biological processes, homeostasis, circadian rhythms and development. AhR is 
located in the cytoplasm where the inducer can bind to it. Two cytoplasmic factors,

HSP90 (heat shock protein 90) and AIP (AhR-interacting protein) enhance receptivity for ligand and help maintain configuration for ligand binding. After ligand binding, both factors dissociate and the liganded AhR is able to enter the nucleus and bind to ARNT.

Together, this transcription complex binds to the enhancer element of the CYP1A1 gene.

Components interact and the initiation complex forms at the promoter, thus starting transcription and leading to metabolism of the ligand (Whitlock, 1999; Hankinson, 1995).

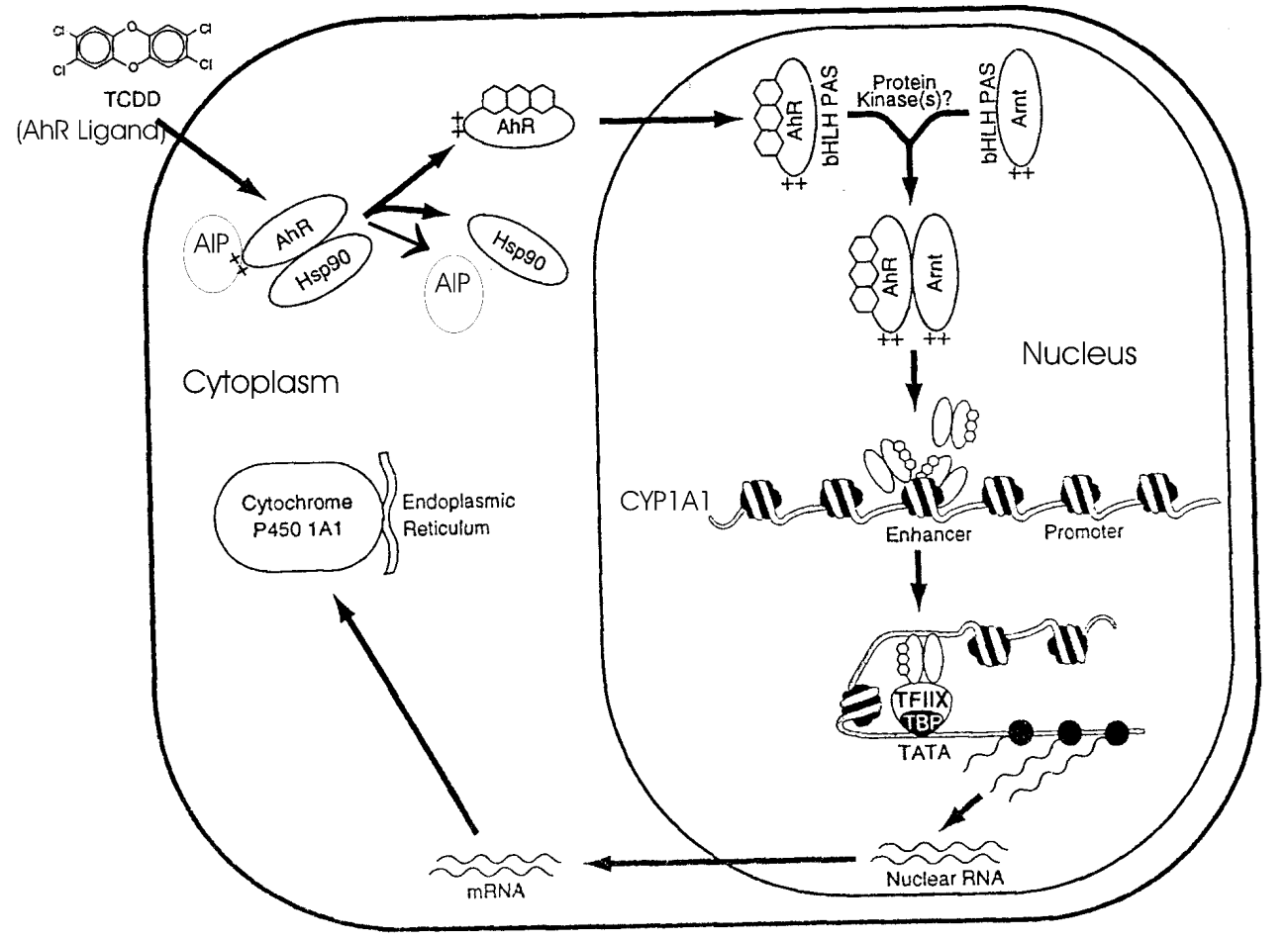

Figure 3. Mechanism of CYP1A1 Induction. Adapted from James Whitlock et al, 1996. 


\section{3 - CYP1A1 and Carcinogenesis}

In general, CYP1A1 has low constitutive expression, but induction occurs rapidly and high expression can be induced. CYP1A1 induction can lead to toxicity or carcinogenesis as a result of the oxidation of the PAHs. For example, PAHs are found in cigarette smoke and their oxygenation by CYP1A1 generates arene oxides that can form DNA adducts resulting in lung cancer.

CYP1A1 Catalyzed Reaction<smiles>CC(C)C(C)(C)C</smiles>

Benzo(a)pyrene

Procarcinogen
Benzo(a)pyrene

7,8 diol-9, 10 epoxide

Ultimate Carcinogen

Figure 4. CYP1A1 Reaction: Procarcinogen to Ultimate Carcinogen 


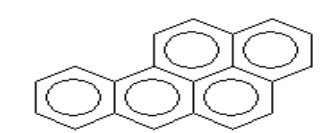

B P

Metabolic Activation to Diol Epoxides
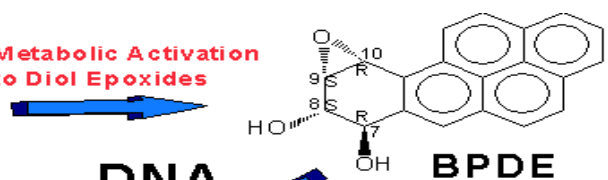

DNA

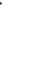

BPDE
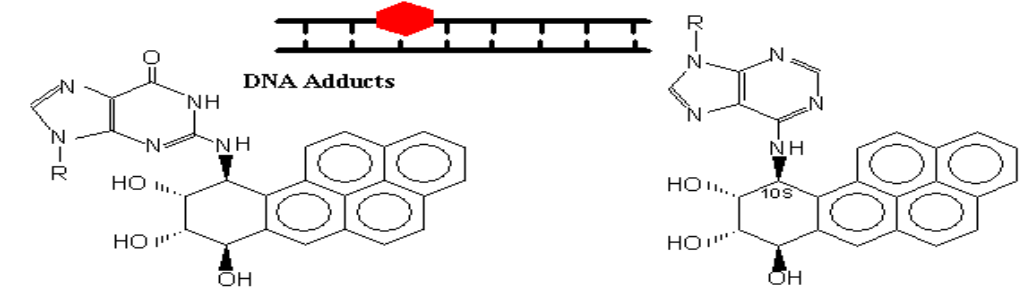

$\square=B P D E-d G$

O $\mathbf{r}$

BPDE-dA

(Covalent DNA adducts)

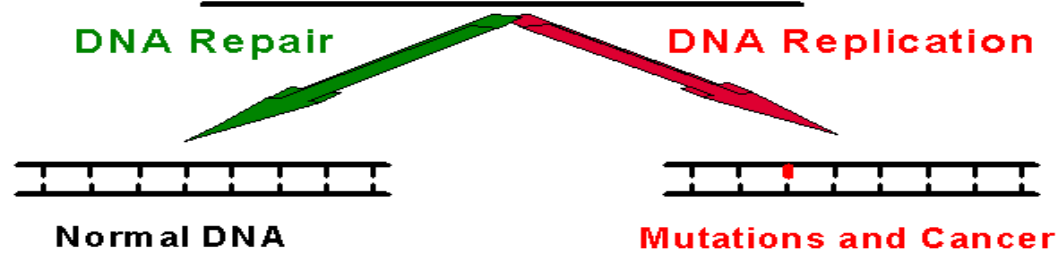

Figure 5. CYP1A1 Metabolism Pathways. Adapted from Geacintov, N.E.; http://www.nyu.edu/projects/geacintov/images/WEB Figures/WEB PAH3.htm

CYP enzymes have been studied for their role in the activation and detoxification

of chemical carcinogenesis. Causes of cancer vary and genetic factors, exposure to

chemicals, and diet are all important considerations. Genetics alone is only thought to

account for about $5 \%$ of all cancers (Perera, 1997). The rest involved environmental

factors which often interact with both genetics and susceptibility (Perera, 1997).

Guengerich and Shimada (1998) summarized evidence of a link between CYP enzymes

and cancer:

1 - cancer susceptibility associated with CYP activity. 
2- variation in level of CYP enzyme basal expression on the individual exposure patterns (work, diet).

3- variations in drug sensitivity and interactions.

\section{4 - Polymorphisms in CYPs}

Several CYP1A1 polymorphism have been found and there is a wide variety of levels of induced enzyme activity among individuals (Daly et al, 1998; Guengerich and Shimada, 1998). In 1973, Kellerman first showed the association between high AHH inductions and bronchiogenic carcinomas in cultured lymphocytes (Smith et al, 2001).

Recent studies have shown several prominent polymorphs associated with lung cancer. The MspI mutation at the $3^{\prime}$ flank that causes a $\mathrm{T}$ to $\mathrm{C}$ transition and a mutation at the Exon 7 heme binding region that causes an A to $\mathrm{G}$ transition which leads to an ILE to VAL substitution are two well known polymorphism in the CYP1A1 gene. A third polymorphism has also been found exclusively among people of African origin MSP1AA (Smith et al, 2001). Most studies on human polymorphisms of CYP1A1 and AhR are still controversial. Some studies have shown increased risk for lung cancer in specific ethnic groups and differences between male and female sex populations for individuals carrying one copy of the variant allele (Smith et al, 2001). There is a wide variance in CYP1A1 expression (50X) in human lung tissue, perhaps explaining the 
varying outcomes between studies. The variation can be due to both genetic

polymorphism or other genes involved in CYP1A1 expression (Alexandrov et al, 2002).

Cigarette smoking has long been considered an important factor in lung cancer.

Cigarette smoke contains PAHs that are bioactivated by CYP1A1. The link between

CYP1A1 polymorphism and lung cancer is still controversial and results are conflicting (Smith et al, 2001).

We must also consider the phase II enzymes and their role in carcinogenesis.

They are responsible for detoxifying the reactive metabolite that is the product of phase I

metabolism. Examples of phase II enzymes include transaminases, acetyltransferases, UDP glucuronyl-, and glutathione-S-transferases (GSTs) that play a huge role in the detoxification of endogenous and exogenous compounds. There are several polymorphisms of GSTs and in most cases, the polymorphs are less effective in the detoxification processes, leading to an increase in cancer risk (Mucci et al, 2001). 


\section{5 - Lung physiology}

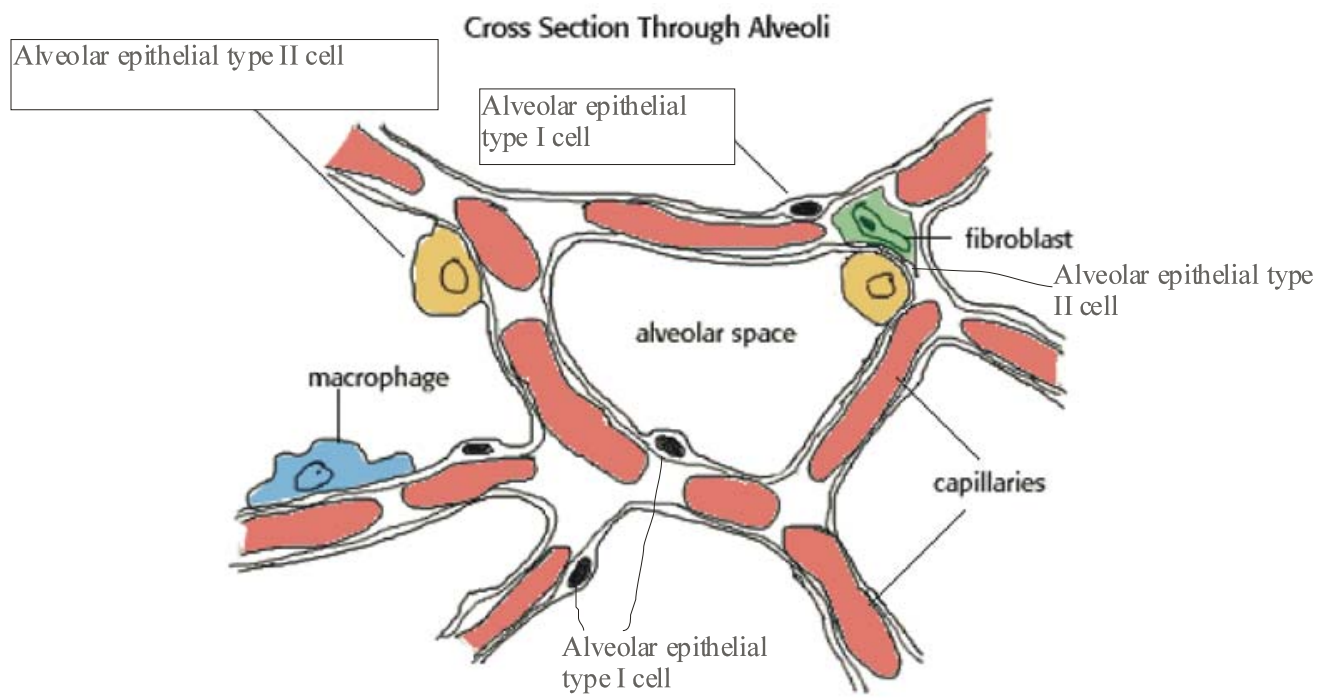

Figure 6. Diagram of lung alveolus. Adapted from

http:www.biology.arizona.edu/chh/problem_sets/lung_toxicology/graphics/alveolus.

Over 40 different cell types have been identified in the lung. There are several

that are important in our research. Alveolar type I cells facilitate gas exchange, help

maintain the alveolar structure, and comprise $96 \%$ of the alveolar surface. Alveolar type

II cells account for $10-15 \%$ of all lung cells but only $4 \%$ of the surface area of the

alveoli (Castranova et al, 1988). On a cell number basis, the type II cells account for

$60 \%$ of all alveolar cells. Type II cells synthesize and secrete surfactant and are the

progenitors of the type I cells. Type II cells also have roles in xenobiotic metabolism

and lung damage repair. Once stimulated, they release cytokines and recruit neutrophils.

Another epithelial cell, the Clara cell is a non-ciliated airway epithelial cell found mostly 
in bronchioles. These cells can differentiate into ciliated cells, participate in xenobiotic metabolism and possibly have a role in surfactant production (Devereux, 1984).

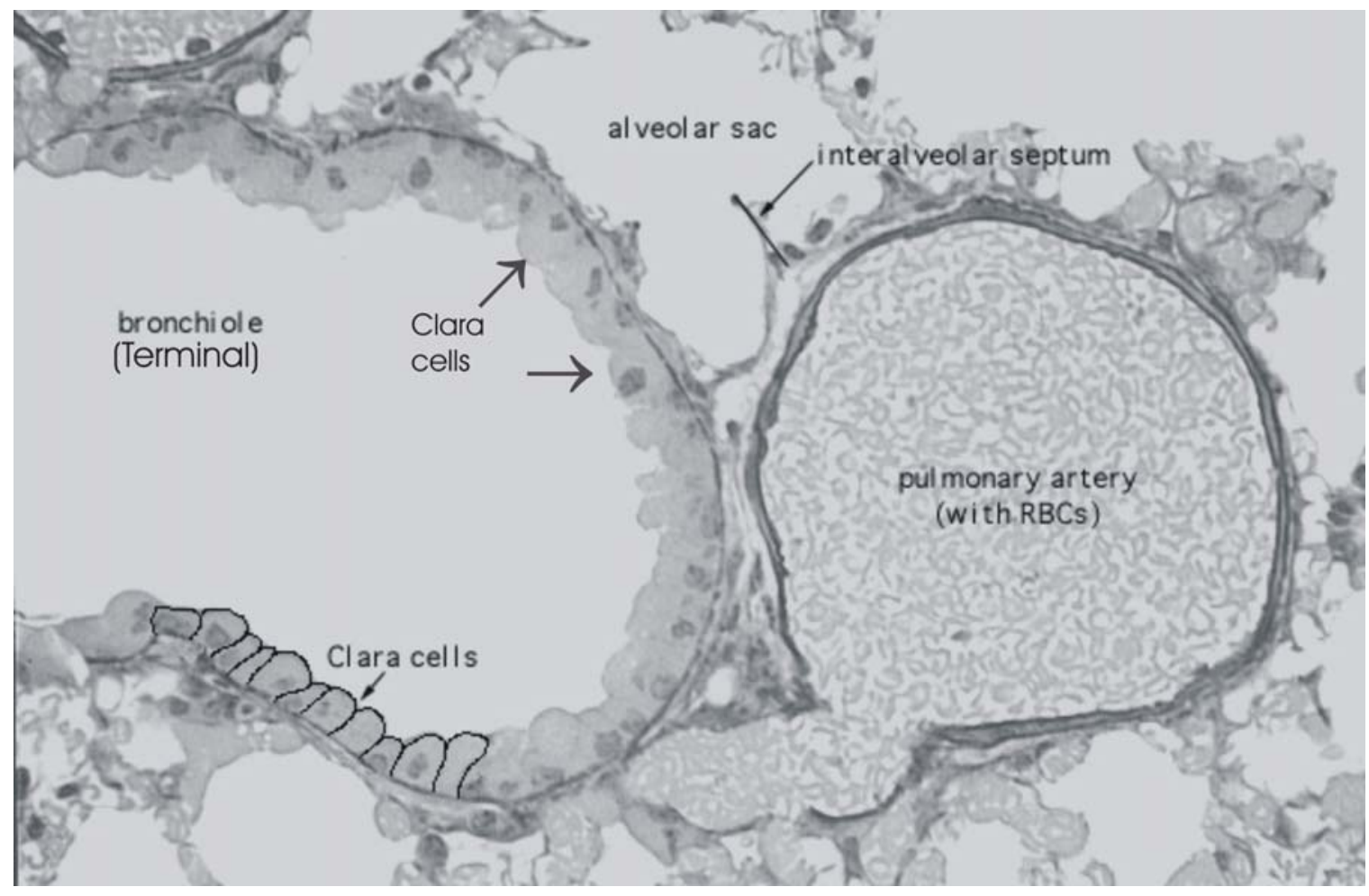

Figure 7. Example of terminal bronchi and Clara Cells. Adapted from http://www.bu.edu/histology/p/13805loa.htm.

Another distinct lung cell type, the alveolar macrophage acts as the first line of defense against inhaled particles and bacteria by engulfing the foreign particles. Several studies have been performed showing xenobiotic metabolism in the alveolar Type II cell and the Clara cell (Devereux, 1984). Methods for isolating several cell types have been discovered enabling us to conduct toxicological and mechanistic studies on specific cells (Castranova et al, 1988). 
Many xenobiotic compounds are aerosolized and easily inhaled by the lungs,

making the lungs an easy target organ. In addition, the lung is a highly vascular organ which makes it a potential target organ for circulating xenobiotics. Lung injury can vary depending on physical and chemical nature of compound, size and concentration of particle and the potential clearance of the agent (Thiedemann, et al, 1991). The lung has two major clearance mechanisms - ciliated epithelium in the trachea and bronchi and phagocytosis by alveolar macrophages (Stuart, 1976). Particles can become trapped in the lung and the resulting persistence facilitates alterations in lung tissues. Chronic and high exposures to respirable particles can cause overload and lead to fibrosis and cancers (Thiedemann et al, 1991; Oberdörster et al, 1997). Lung particle overload is associated with lung inflammation, accumulation of particles in centriacinar interstitial and alveolar areas of the lung, type II cell proliferation, and impaired macrophage clearance ability in the rat lung (Oberdörster et al, 1995; ILSI Risk Science Institute Workshop, 2000).

\section{$\underline{6 \text { - Respirable Crystalline Silica }}$}

Respirable sized particles reach the alveolar region of the lung. In experimental animal research, there are 2 common ways to expose animals to particles - inhalation or intratracheal instillation. Both procedures have advantages and disadvantages.

Intratracheal instillation is inexpensive and a known amount of material is dosed to the lung. However, this method does not accurately reflect human exposures to particles. 
Research has shown differences in particle distribution, clearance and injury pattern. The particle distribution is less homogenous in intratracheal instillations than in inhalation exposures, creating a variance of particle burden in the lung (Osier and Oberdörster, 1997). It has been reported that at low level particle exposures the total lung burden is not different between the techniques (Ferin and Feldstein, 1978). A comparison study determined that either method was useful to assess pulmonary responses (Henderson et al, 1995). Inhalation can be very expensive and the amount of dosed material is not measured as accurately, but this is the more natural exposure method. (Brain et al, 1976; Osier and Oberdörster, 1997; Driscoll et al, 2000).

Crystalline silica has many polymorphic forms - $\alpha$-quartz, $\beta$-quartz, crystoballite (NIOSH Hazard Review, 2002). Individuals can be exposed to crystalline silica in several occupational settings (e.g. coal mining, sand blasting) if protective measures are not taken. Silicosis is chronic lung disease caused by inhalation exposure to respirable crystalline silica. Silicosis can be acute (short exposure to a high concentration) or chronic (long exposure to low concentration). It can also be latent, occurring years after the initial exposure to silica. In 1997, IARC found enough evidence to add respirable crystalline silica to its list of agents that are carcinogenic to humans (IARC Monograph, 1997). 
Respirable exposure to crystalline silica causes an inflammatory response in pulmonary cells and tissues (Castranova, 2000; Porter et al, 2001; Driscoll et al, 1990; Driscoll et al, 1991). Several cell types are involved in the development of silicosis. Macrophages try to engulf the particles and phagocytose them (Miller et al 1986; Miller et al 1987; Miller and Hook, 1990). Lavage studies have shown increases (2x control) in the number of polymorphonuclear leukocytes (PMN's) in silica exposed rats, indicating inflammation. Surfactant production is increased in the alveolar type II cell and they become hyperplastic and hypertrophied in response to silica (Miller et al, 1987). Total protein and phospholipid numbers in bronchial lavage fluid also increase in the silica exposed lung (Dethloff et al, 1986; Miles et al, 1993; Miles et al, 1994). The type I cell is damaged and stimulates proliferation of the type II cell to replace the dead type I cell (hyperplasia). Surfactant production increases; the type II cells of silicosis frequently contain abundant surfactant apoprotein and are enlarged (hypertrophic) (Miller and Hook, 1990).

Reactive oxygen species (ROS) are also generated during chronic silica exposures (Vallyathan et al, 1998). ROS are produced at both the particle surface and by the phagocytizing cells engulfing the particle (Fubini and Hubbard, 2003). ROS cause cytotoxic lung injury through release of oxidants. These oxidants activate cell signaling pathways, enhancing inflammatory cytokine expression, and activating transcription 
factors. Oxidant effects include NFKB activation, AP-1 activation, and TNF alpha production. Apoptosis can also be induced by ROS (Fubini et al, 2003).

Oxidants can activate oncogenes or inactivate tumor suppressor genes and lead to carcinogenesis. Hydroxy radicals $(\cdot \mathrm{OH})$ have been shown to cause DNA breaks and damage that can lead to carcinogenesis via point mutations and deletions (Jackson, 1994).

The release of inflammatory cytokines such as TNF $\alpha$ and IL1 $\beta$, and IL6 has been shown to inhibit CYP1A1 expression (Jackson, 1994; Morgan, 2001). The mechanism of this down regulation is still being investigated. Several findings include:

The release of TNF alpha can induce the release of NO, which is then able to bind to the heme portion of the CYP. This binding then inhibits activity of the enzyme. NO can also react with oxygen causing a loss in catalytic activity (Paton and Renton, 1998). NFKB is also induced by TNF $\alpha$. NFKB plays an important role in several necessary biological processes, including - immune response, inflammatory regulation, cell proliferation, apoptosis, and developmental processes (Ke et al, 2001). NFKB is a heterodimer made up of p65 (relA) and p50. A link between the AhR and NFKB signaling pathway indicates a mechanism for inflammatory mediators to inhibit CYP1A1 expression (Ke et al, 2001). RelA (P65 subunit of NFKB) and AhR complexes interact and RelA is able to inhibit activation of CYP1A1 transcription (Tian et al, 1999). Ke et al, (2001) suggests that the activation of NFKB remodels the chromatin of the 
CYP1A1 promoter. Their data suggest a possible mechanism for the suppression of CYP1A1 by inflammation - pro-inflammatory cytokines such as TNF $\alpha$ induce NFKB, the RelA subunit interacts with AhR and inhibits activation resulting in down regulation of CYP1A1 expression (Ke et al 2001; Tian et al, 1999; Tian et al, 2002). 


\section{Chapter 3}

\section{Methods and Materials}

\section{1 - Preparation of Silica}

Crystalline Silica ( $\alpha$-quartz) was obtained from Min-U-Sil, (U.S. Silica, Berkeley Springs, WV). It was fractionated to $<5$ um using a Donaldson particle classifier. By Xray diffraction (XRD) it was pure crystalline silica (99.8\%) and by X-ray spectrometry (particle analysis) it was $98.7 \%$ pure. Surface area measurements were done by nitrogen adsorption technique. Mean surface area of $<5 \mathrm{Min}-\mathrm{U}-\mathrm{Sil}$ is $4.7 \mathrm{~m}^{2} /$ gram. Mass median aerodynamic diameter (MMAD) of silica is $3.5 \mathrm{um}$. Prior to instilling, the silica was sterilized by heating overnight in an oven at $160^{\circ} \mathrm{C}$. Sterile silica particles were weighed and then suspended in $0.9 \%$ sodium chloride (Abbot Laboratories, North Chicago, IL) to produce 5,10 , or $20 \mathrm{mg} / 0.5 \mathrm{ml}$ solutions. Representative samples of the sterilized silica and the saline solution were analyzed for endotoxin. Measurements were determined by the Limulus Amebocyte Lysate assay (BioWhitaker, Walkersville, MD).

\section{2 - Preparation of CYP Inducers}

Corn oil (Mazola, Englewood Cliffs, NJ) was filtered through a $0.2 \mu \mathrm{m}$ membrane syringe filter. A $100 \mathrm{mg} / \mathrm{ml}$ solution of Phenobarbital (Sigma Chemical, St. Louis, MO) was prepared with corn oil. $50 \mathrm{mg} / \mathrm{ml}$ solution of $\beta$-naphthoflavone (Sigma Chemical, St. Louis, MO) was prepared with corn oil. These solutions were mixed in sterile centrifuge tubes, vortexed and then sonicated for at least 20 minutes. 


\section{3- The Rat Model of Silicosis}

Male, Sprague-Dawley, Hla:(SD)CVF rats (Hilltop Lab Animals, Scottdale, PA) weighing between 125 and 150 grams on arrival were used for these experiments. Rats were housed in shoebox cages supplied with HEPA-filtered laminar flow air with AlphiDri Virgin cellulose chips (Sheperd Specialty Papers, Watertown, TN) and hardwood Beta-chips (NEPCO, Warrensburg, NY) for bedding, and provided tap water and autoclaved ProLab 3500 (Purina Mills Incorporated, St. Louis, MO) rodent diet ad libitum. Rats were allowed to acclimate to the animal facility for one week.

Prior to exposure, rats were randomly placed into exposure groups using a table of random numbers. Animals were anesthesized with an intraperitoneal injection (IP) of 35/mg/kg Brevital Sodium (Methohexital sodium, Eli Lilly and Co., Indianapolis, IN) and received an intratracheal instillation (IT) of $0.5 \mathrm{ml}$ of the silica suspension $(5,10$ or $20 \mathrm{mg}$ crystalline silica) or the vehicle alone ( $0.9 \%$ sodium chloride). To determine if silicosis suppressed the induction of CYP1A1 or the constituitive expression of CYP2B1 in the lung, rats with and without silicosis were exposed to the CYP1A1 inducer, $\beta$ naphthoflavone (NF). Some of these rats were exposed to the hepatic-specific CYP2B1 inducer, phenobarbital, because phenobarbital is a CYP2B1 inducer in the liver and has not been investigated in the silicotic lung.

\section{4 - Experiment 1; Exposures to Silica (IT) Classical Inducers of CYP1A1 and}

\section{CYP2B1}

Seventeen rats received intratracheal instillations of $20 \mathrm{mg}$ silica and twenty rats received saline. Rats were sacrificed 14 days post IT exposure. Rats received CYP inducer and/or vehicle via intraperitoneal injection on days 11 and 13 after IT instillation 
as outlined in table M1. These treatments resulted in the following groups of rats: control rats, rats with NF induced pulmonary CYP1A1, phenobarbital exposed rats, phenobarbital exposed rats with NF induced CYP1A1, silica exposed rats, silica exposed rats with NF induced CYP1A1, silica and phenobarbital exposed rats, and silica and phenobarbital exposed rats with NF induced CYP1A1.

Table M1: Experimental Design

\begin{tabular}{|c|c|c|c|c|c|c|c|c|}
\hline Group & Control & $\begin{array}{l}\text { CYP1A1 } \\
\text { induced }\end{array}$ & $\begin{array}{l}\text { Phenobarbi } \\
\text {-tal } \\
\text { exposed }\end{array}$ & $\begin{array}{l}\text { Phenobarbi- } \\
\text { tal exposed } \\
\text { \& CYP1A1 } \\
\text { induced }\end{array}$ & $\begin{array}{l}\text { Silica } \\
\text { Exposed }\end{array}$ & $\begin{array}{l}\text { Silica } \\
\text { Exposed } \\
\& \\
\text { CYP1A1 } \\
\text { induced }\end{array}$ & $\begin{array}{l}\text { Silica \& } \\
\text { Pheno- } \\
\text { barbital } \\
\text { exposed }\end{array}$ & $\begin{array}{l}\text { Silica \& } \\
\text { Pheno- } \\
\text { barbital } \\
\text { exposed } \\
\& \\
\text { CYP1A1 } \\
\text { induced }\end{array}$ \\
\hline $\begin{array}{l}\text { Intratra- } \\
\text { cheal } \\
\text { instilla- } \\
\text { tion } \\
\text { Day 0 }\end{array}$ & $\begin{array}{l}\text { Saline } \\
0.5 \mathrm{ml}\end{array}$ & $\begin{array}{l}\text { Saline } \\
0.5 \mathrm{ml}\end{array}$ & $\begin{array}{l}\text { Saline } \\
0.5 \mathrm{ml}\end{array}$ & $\begin{array}{l}\text { Saline } \\
0.5 \mathrm{ml}\end{array}$ & $\begin{array}{l}\text { Silica } \\
20 \mathrm{mg}\end{array}$ & $\begin{array}{l}\text { Silica } \\
20 \mathrm{mg}\end{array}$ & $\begin{array}{l}\text { Silica } \\
20 \mathrm{mg}\end{array}$ & $\begin{array}{l}\text { Silica } \\
20 \mathrm{mg}\end{array}$ \\
\hline $\begin{array}{l}\text { Intraperito } \\
\text { neal } \\
\text { injection } \\
\text { Day } 11\end{array}$ & $\begin{array}{l}\text { Corn } \\
\text { Oil }\end{array}$ & $\mathrm{NF}^{\mathrm{a}}$ & $\mathrm{PB}^{\mathrm{b}}$ & $\mathrm{NF}^{\mathrm{a}} \& \mathrm{~PB}^{\mathrm{b}}$ & Corn oil & $\mathrm{NF}^{\mathrm{a}}$ & $\mathrm{PB}^{\mathrm{b}}$ & $\begin{array}{l}\mathrm{NF}^{\mathrm{a}} \& \\
\mathrm{~PB}^{\mathrm{b}}\end{array}$ \\
\hline $\begin{array}{l}\text { Intraperito } \\
\text { neal } \\
\text { injection } \\
\text { Day } 13\end{array}$ & $\begin{array}{l}\text { Corn } \\
\text { Oil }\end{array}$ & Corn Oil & $\mathrm{PB}^{\mathrm{b}}$ & $\begin{array}{l}\mathrm{PB}^{\mathrm{b}} \& \\
\text { Corn oil }\end{array}$ & $\begin{array}{l}\text { Corn } \\
\text { Oil }\end{array}$ & Corn Oil & $\mathrm{PB}^{\mathrm{b}}$ & $\begin{array}{l}\mathrm{PB}^{\mathrm{b}} \& \\
\text { Corn } \\
\text { Oil }\end{array}$ \\
\hline $\begin{array}{l}\# \text { of } \\
\text { animals }^{\mathrm{c}}\end{array}$ & 5 & 5 & 4 & 5 & 4 & 3 & 4 & 4 \\
\hline
\end{tabular}

a. $\mathrm{NF}=\beta$-naphthoflavone $(50 \mathrm{mg} / \mathrm{kg})$ in corn oil;

b. $\mathrm{PB}=$ Phenobarbital $(100 \mathrm{mg} / \mathrm{kg})$

c. Number of animals remaining at time of sacrifice. Experiment started with 5 animals per group. Animal deaths resulted from intraperitoneal injections.

End Points Measured: Pulmonary CYP1A1 and total CYP activity were measured with EROD and ECOD activity, respectively. CYP1A1 and CYP2B1 lung tissue expression was localized with enzymatic immunohistochemistry to the sites of expression. Histopathology was performed to assess lung injury. 


\section{5 - Experiment 2: Exposures to Silica and BNF, a Classical Inducer of CYP1A1}

12 rats were intratracheally instilled with $20 \mathrm{mg}$ silica and another 12 rats instilled with saline. 11 days after instillation, 6 rats from each group were weighed and injected intraperitoneally with $50 \mathrm{mg} / \mathrm{kg} \beta$-naphthoflavone or vehicle alone (corn oil).

Table M2: Experimental Design for Experiment 2

\begin{tabular}{|l|l|l|l|l|}
\hline Group & Control & NF exposed & Silica exposed & $\begin{array}{l}\text { Silica \& NF } \\
\text { exposed }\end{array}$ \\
\hline Intratracheal & Saline & Saline & Silica & Silica \\
\hline $\begin{array}{l}\text { CYP1A1 } \\
\text { Inducer }\end{array}$ & Corn Oil & NF & Corn Oil & NF \\
\hline \# of animals & 6 & 6 & 6 & 6 \\
\hline
\end{tabular}

$\mathrm{NF}=\beta$-naphthaflavone in corn oil

End Points Measured: CYP1A1 and CYP2B1 activity were measured by EROD and PROD activity respectively. CYP1A1 protein was measured by western blot, and CYP1A1 expression was localized within lung tissue by CYP1A1 immunofluorescence using dual immunofluorescence wih cytokeratin 8 , a marker of alveolar type II cells in the lung alveolus. Histopathology was used to assess lung injury.

\section{6 - Experiment 3: Silica Dose Response Study with Exposure to Classical Inducer of}

\section{CYP1A1}

Five rats were intratracheally instilled with saline, $5 \mathrm{mg}$ silica, or $10 \mathrm{mg}$ silica and four rats were intratracheally instilled with $20 \mathrm{mg}$ silica. Eleven days later, all rats received a $50 \mathrm{mg} / \mathrm{kg}$ IP injections of NF. 
Table M3: Experimental Design for Experiment 3

\begin{tabular}{|l|l|l|l|l|}
\hline Groups & NF Control & $\mathrm{NF} /$ low dose & $\mathrm{NF} /$ mid dose & $\mathrm{NF} /$ high dose \\
\hline Intratracheal & Saline & $5 \mathrm{mg}$ Silca & $10 \mathrm{mg}$ Silica & $20 \mathrm{mg}$ Silica \\
\hline $\begin{array}{l}\text { CYP1A1 } \\
\text { Inducer }\end{array}$ & $\mathrm{NF}$ & $\mathrm{NF}$ & $\mathrm{NF}$ & $\mathrm{NF}$ \\
\hline \# of animals* & 5 & 5 & 5 & 4 \\
\hline
\end{tabular}

$\mathrm{NF}=\beta$-naphthaflavone in corn oil

* = Number of animals at time of sacrifice. One animal died as a result of intraperitoneal injection.

End Points Measured: CYP1A1 and CYP2B1 activity were measured by EROD and PROD activity, respectively. CYP1A1 and CYP2B1 protein were measured by western blot. Histopathology was used to assess lung injury.

\section{7-Tissue Collection (Experiments 1, 2, and 3)}

On day 14 after intratracheal instillation, the rats were euthanized. The rats were euthanized by an intraperitoneal injection of an overdose of sodium pentobarbital followed by exsanguination via transection of the abdominal aorta. The lungs were removed and the right lung lobes were isolated, tied off and removed. The right lung lobes were placed on ice and microsomes were isolated as subsequentially described for biochemical analysis. The left lung lobe was inflated via the trachea with $3 \mathrm{ml}$ of neutral buffered formalin, tied off and placed in a sealed bag with $10 \%$ neutral buffered formalin $(10 \% \mathrm{NBF})$. The tracheobronchial lymph node, parathymic lymph node, liver and kidney were also collected and placed in $10 \%$ neutral buffered formalin. 


\section{8 - Biochemical Analysis; Preparation of Lung Microsomes (Experiments 1, 2, and}

3)

Microsomes were prepared as described by Miles et al, 1993 and Ma et al, 2002. At necropsy, the right lung lobes were weighed and placed on ice. The lung tissue was was chopped using a McIllwain tissue chopper (The Mickle Engineering Co., Gomshall, Surrey, UK). Tissues were chopped atleast 4 times with slice thickness set at $5 \mathrm{~mm}$. Ice cold buffered solution $\left(145 \mathrm{mM} \mathrm{KCl}, 30 \mathrm{mM}\right.$ Tris- $\mathrm{HCl}, 1.9 \mathrm{mM} \mathrm{KH}_{2} \mathrm{PO}_{4}$, and $3 \mathrm{mM}$ $\mathrm{MgCl}_{2}, \mathrm{pH} 7.4$ ) was added to the tissue homogenate at $25 \% \mathrm{wt} / \mathrm{vol}$ ratio. A teflon-glass Potter-Elvejhem homogenizer was used to make a homogenate (16 complete passes with the pestle). Four sequential centrifugaions were performed to obtain the microsomal fraction. The first spin was for 10 minutes at 1000 times $\mathrm{g}$. The next three centrifugations were for 20 minutes each at 3,000, 10,000, and 15,000 times g. Using an ultracentrifuge, the microsomal fraction was obatined by centrifuging at 105,000 x $\mathrm{g}$ for 75 minutes. The microsomal pellet was resuspended in cold buffered solution, aliquoted and frozen at $-80^{\circ} \mathrm{C}$.

\section{9 - Biochemical Analysis; Measurement of CYP1A1 protein activity by}

\section{Ethoxyresorufin-O-deethylase (EROD) Activity (Experiment 1, 2, and 3)}

CYP1A1 protein activity was measured in isolated microsomes stored at $-80 \mathrm{C}$.

EROD was measured as previously described (Burke and Mayer, 1974; Burke et al, 1985; Miles et al, 1993). Reactions were carried out in fluorimeter cuvettes that contained $150 \mu \mathrm{l}$ of microsomes, $2.78 \mathrm{ml}$ phosphate buffer (145 mM KCL, $1.9 \mathrm{mM}$ $\mathrm{KH}_{2} \mathrm{PO}_{4}, 8.1 \mathrm{mM} \mathrm{K}_{2} \mathrm{HPO}_{4}, 30 \mathrm{mM}$ Tris-HCL, and $3 \mathrm{mM} \mathrm{Mg} \mathrm{Cl}$; $\mathrm{pH}$ 7.6), $9 \mu 1$ 7-ethoxyresorufin $(3 \mu \mathrm{M}), 7.5 \mu$ dicumarol $(25 \mu \mathrm{M})$. The dicumarol was added to prevent the 
interference resulting from the elevated quinone oxidoreductase levels found in preparations from animals pretreated with xenobiotics (Burke et al, 1985). The mixture was allowed to equilibrate for 1 minute at $37^{\circ} \mathrm{C}$ and then $50 \mu 1$ of reduced form of NADPH $(28.8 \mathrm{mM})$ was added to initiate the reaction. The reaction for the first experiment was carried out for 8 minutes and was measured at various time points to replicate the method of Miles and co-workers (Miles et al, 1993). For the second and third experiments, the reaction was measured by measuring the optical density every minute for 10 sequential minutes (Ma et al, 2002). Under these conditions, increases in the fluorescence are due solely to CYP dependent formation of a single metabolite, resorufin, from the substrate used (Burke et al, 1985). The flourimetric settings were 530 $\mathrm{nm}$ and $585 \mathrm{~nm}$ for the excitation and emission respectively, and $6.5 \mathrm{~nm}$ for the excitation and emission slit. A standard curve was determined after each run using a $10 \mu \mathrm{M}$ resorufin solution prepared from $2.35 \mu \mathrm{g}$ resorufin in $1 \mathrm{ml}$ DMSO. For compatability with the previous experiments of Miles and co-workers (Miles et al 1993; Miles et al,1994) EROD activity for the first experiment was expressed as $\mathrm{pmol} / \mathrm{mg} / \mathrm{microsomal}$ protein $/ 8$ minutes or as pmol/lung/ 8 minutes. For the second and third experiments, EROD was expressed as $\mathrm{pmol} / \mathrm{min} / \mathrm{mg}$ microsomal protein or $\mathrm{pmol} / \mathrm{min} / \mathrm{lung}$ for comparability with other studies of particle effects in the lung (Ghanem et al, 2004).

\section{0 - Measurement of Cytochrome P450 - ECOD (Experiment 1)}

ECOD was measured as previously described (Ullrich and Weber, 1972; Burke et al, 1985; Miles et al, 1993). As with EROD, the activity of ECOD was measured using microsomes stored at $-80^{\circ} \mathrm{C}$. The cuvettes contained a total volume of $6 \mathrm{ml}$, which 
contained of $0.1 \mathrm{mg}$ protein per milliliter incubation medium lung microsomes, $0.5 \mathrm{mg} / \mathrm{ml}$ bovine serum albumin, $0.48 \mathrm{mM} \mathrm{NADPH}$, and $0.5 \mathrm{mM}$ of 7-Ethoxycoumarin -Odeethylase. The reaction was initiated by the addition of 7- Ethoxycoumarin -Odeethylase in dimethyl sulfoxide (DMSO) $(5 \mu 1 / \mathrm{ml})$ and carried out at $37^{\circ} \mathrm{C}$ for 30 minutes. Umbelliferone, the reaction product, was measured after 30 minutes using a fluorometer as described by Ullrich and Weber, 1972. A model LS-50 Luminescence Spectrophotometer (Perkin-Elmer Corp., Norwalk, CT) was used for measurements and results were expressed as $\mathrm{pmol} / \mathrm{mg} / \mathrm{microsomal}$ protein $/ 30$ minutes or $\mathrm{pmol} / \mathrm{lung} / 30$ minutes.

\section{1 - Measurement of the CYP2B1 - Dependent Enzymatic Activities}

\section{(PROD) (Experiments 2 and 3)}

This assay was performed as previously described (Burke et al, 1985; Ma, et al, 2002). The procedure was similar to EROD except the sample volume of the microsomes used was increased $(300 \mu \mathrm{l})$. Also the substrate used for the reaction was 7pentoxy-resorufin. Resorufin was also used to determine the standard curve. Results were expressed as $\mathrm{pmol} / \mathrm{min} / \mathrm{mg} / \mathrm{microsomal}$ protein or $\mathrm{pmol} / \mathrm{min} / \mathrm{lung}$.

\section{2 - Determination of the Total Lung Proteins: (Experiments 1, 2, and 3)}

The bicinchonicic acid (BCA) method (Pierce, Rockford, IL) was used to measure the protein content of the lung microsomes. Bovine serum albumin was used as the standard and the 96 well plates were read on a spectrophotometer (Spectramax 250, Molecular Devices Corporation, Sunnyvale, CA). 


\section{3 - Western Blot Analysis - (Experiment 2 and 3:CYP1A1, Experiment 3:}

\section{$\underline{\text { CYP2B1) }}$}

Lung microsomes were used to quantify the amount of CYP1A1 or CYP2B1 per mg microsomal protein. The procedure was performed as described by Ma et al, 2003 . Microsome samples were thawed on ice and protein was placed in an eppendorf tube (75 $\mu \mathrm{g}$ for Experiment $2 \mathrm{CYP} 1 \mathrm{~A} 1,37.5 \mu \mathrm{g}$ for Experiment $3 \mathrm{CYP} 1 \mathrm{~A} 1$, and $20 \mu \mathrm{g}$ for Experiment 3 CYP2B1). BNF treated rat liver microsomes (Xenotech, Kansas City, Kansas) diluted 1:100 with $2 \mathrm{X}$ loading buffer (Invitrogen, Carlsbad, CA) were used at a positive control for CYP1A1 expression and phenobarbital treated rat liver microsomes (Xenotech, Kansas City, Kansas) diluted 1:10 with $2 \mathrm{X}$ loading buffer were used as a positive control for CYP2B1. The rainbow color marker (Multimark ${ }^{\mathrm{TM}}$, Invitrogen, Carlsbad, CA), and the molecular weight marker (Magicmark ${ }^{\mathrm{TM}}$, Invitrogen, Carlsbad, CA) were mixed 1:2 with 2X SDS Loading buffer (Invitrogen, Carlsbad, CA). All samples were then vortexed, heated at $95^{\circ} \mathrm{C}$ for 5 minutes and allowed to cool before vortexing again and centrifuged for $10-15$ seconds. $1.5 \mathrm{~mm}$ tris-glycine gels (Invitrogen, Carlsbad, CA) were used to load the samples. Microsome samples were loaded into the gel. $10 \mu \mathrm{l}$ of positive control and color marker, and $5 \mu 1$ of molecular weight marker were also loaded on every gel. Gels were electrophoresed in $1 \mathrm{X}$ running buffer (Invitrogen, Carlsbad, CA) using an Xcell SureLock Mini Cell ${ }^{\mathrm{TM}}$ (Invitrogen, Carlsbad, CA) with a BIORAD power supply (BioRad, Hercules, CA). After 90 minutes at 125 volts, the gels were removed and transferred onto nitrocellulose membranes using the Xcell II ${ }^{\mathrm{TM}}$ Blot Module (Invitrogen, Carlsbad, CA). The transfer was completed after 90 minutes at 25 volts in transfer buffer. Gels were then discarded and the membranes 
were blocked with a 5\% milk solution for at least one hour on a rocker. The membranes were then washed in tris-buffered saline with $0.1 \%$ Tween (TBS-T) for 5 to 15 minutes. The primary antibody, a polyclonal, affinity purified rabbit anti-rat CYP1A1 (Xenotech, Kansas City, Kansas) or Mouse anti-rat CYP2B1 (Xenotech, Kansas City, Kansas) was diluted 1:1000 with $1 \%$ milk and allowed to incubate on the membrane overnight on a rocker at $4 \mathrm{C}$. The membrane was then washed in TBS-T for 5 to 15 minutes each before applying the secondary antibody. The secondary antibody was either HRP conjugated goat anti-rabbit IgG (for CYP1A1) or goat anti-mouse IgG (for CYP2B1) (SantaCruz Biotechnology, Santa Cruz, CA) and was diluted 1:2000 in 1\% milk. Incubation was at room temperature for one hour on a rocker. Membranes were washed again and detection was performed using chemiluminescent reagent (ECL2109, Amersham Buckinghamshire, England). The membranes were incubated for 1 minute with the ECL reagents, blotted, covered with plastic and exposed to undeveloped film for 30 to 60 seconds. Film was developed using an automatic developer (Kodak, Rochester, NY). Film images were scanned using the Eagle Eye II (Stratagene, La Jolla, CA) and the scanned images were quantified using commercial morphometry software (Image Quant 5.1 Molecular Dynamics/Amersham Biosciences, Piscataway, NJ). The volume of each band was quantified 3 separate times and averaged. Data were compared as percent positive control. Negative numbers were considered as zeros. 


\section{4 - Histologic Processing of Tissues (Experiments 1, 2, and 3)}

A section of the left lung lobe was processed and embedded in paraffin within 24 hours of necropsy. The remaining tissues were stored in $10 \%$ NBF until processing. Slides stained with Hematoxylin and Eosin (H \& E) and Masson's Trichrome were prepared from the left lung. Additional tissue sections of each left lung lobe block were cut at 5 microns and placed on silane treated slides (ProbeOn Plus, Fisher Scientific, Pittsburgh, PA) for immunostaining.

\section{5 - Hematoxylin and Eosin Staining of tissues (Experiments 1, 2, and 3)}

The slides were stained on the Shandon Lipshaw Linistain GLX (Thermo Shandon, Pittsburgh, PA) slide stainer. The stainer is set up as follows: 5 baths of xylene, $100 \%$ alcohol, 95\% alcohol, distilled water, Harris hematoxylin, distilled water, bluing solution, distilled water, 95\% alcohol, eosin 95\% alcohol and 100\% alcohol. The slides were placed on the slide stainer and heated at $65^{\circ} \mathrm{C}$ for several minutes before being placed in the first bath. Each bath is approximately 30 seconds long. At the end, the slides were incubated in xylene and coverslipped with Permount.

\section{6 - Masson's Trichrome Staining of tissues (Experiments 1, 2, and 3)}

The slides were deparaffinized as follows: 3 baths of xylene for 6 minutes each, and a 3 minute bath in each of the following: $100 \%$ alcohol, $95 \%$ alcohol, and $80 \%$ alcohol. The slides were finally placed in distilled water for at least 5 minutes before beginning staining. Staining was performed as described by Masson, (1929). Using glass staining dishes, slides were placed in Bouin's solution for 1 hour at $56^{\circ} \mathrm{C}$ then rinsed in running water until yellow color disappears. Slides were rinsed in distilled water and placed in Weigert's iron hematoxylin for 10 minutes and then rinsed in running water for 
10 minutes. After another rinse in distilled water, slides were placed in Biebrich scarletacid fuchsin solution for 2 minutes and rinsed in distilled water. Slides were then placed in Phosphomolybdic-phosphotungstic acid solution for 10 to 15 minutes, followed by a 5 minute bath in Aniline blue solution. The slides were rinsed in distilled water, placed in glacial acetic acid solution for 3 to 5 minutes, and dehydrated and mounted with permount.

\section{7 - Histopathology: Experiments 1, 2, and 3}

Tissue sections from all experiments were examined by a board certified veterinary pathologist who was blinded to exposure status. Tissue sections from the third experiment were scored semi-quantitatively for statistical analysis as previously described (Hubbs et al, 1997). The severity and distribution of the morphologic changes were recorded and converted to quantitative scores for each slide. The numerical transformation is given in Table M4. The pathology score is the sum of the severity and distribution scores which produces a score with a potential range from $0-10$.

Table M4

\begin{tabular}{|c|c|c|}
\hline Score & Severity & Distribution \\
\hline 0 & None & None \\
\hline 1 & Minimal & Focal \\
\hline 2 & Mild & Locally extensive \\
\hline 3 & Moderate & Multifocal \\
\hline 4 & Marked & Multifocal and Coalescent \\
\hline 5 & Severe & Diffuse \\
\hline
\end{tabular}




\section{8 - Enzymatic Immunohistochemistry for CYP1A1 (Experiment 1)}

A modification of the labelled streptavidin-biotin (LSAB) procedure provided by the manufacturer in the commercial kit (LSAB2 Kit, DAKO, Carpinteria, CA) was used in these studies. In this procedure, slides are deparaffinized, antigenicity is retrieved, non-specific peroxidase activity and binding is blocked, a primary antibody is applied, followed by a biotinylated secondary antibody and a streptavidin-enzyme complement. A substrate chromogen is applied to visualize the color reaction and location of the antibody.

For each animal, a slide was incubated with rabbit anti-CYP1A1 polyclonal antibody or rabbit control serum (negative control). Because $\beta$-naphthaflavone (NF) is a strong inducer of CYP1A1, a slide from an animal treated with IT saline and IP NF was included with every group of slides stained to serve as a positive control.

Deparaffinizing: $\quad$ The slides were heated in an oven at $65^{\circ} \mathrm{C}$ for 20 minutes and deparaffinized in fresh solutions of xylene and alcohols. Deparaffinization consisted of six 30 second baths of xylene, one 30 second bath of $100 \%$ alcohol and a 30 second bath of $95 \%$ alcohol, and a 5 minute bath in distilled water.

Blocking for non-specific peroxidase activity and binding: After deparaffinizing, slides are placed in a humidity chamber and 3\% hydrogen peroxide solution was dropped on the slides for a 5 minute incubation at room temperature. Slides were rinsed with distilled water and Tissue Conditioner (Biomeda, Foster City, CA) was applied for 5 minutes at $37^{\circ} \mathrm{C}$. Slides were blotted and placed in a coplin jar with Tris Buffered Saline (TBS (Dako, Carpinteria, CA) for 5 minutes at room temperature. 
Primary antibody application: The primary antibody, rabbit anti-rat CYP1A1/1A2 (Amersham, Buckinghamshire, England) was reconstituted by adding 300 microliters of 1\% BSA/PBS and then diluted 1:4 with Antibody Diluent (Dako, Carpinteria, CA). Rabbit control serum (Biogenex, San Ramon, CA) was applied in place of the primary antibody on negative control slides. The primary antibody or control rabbit serum were applied and the slides incubated overnight at room temperature in the humidity chamber.

Secondary antibody, label antibody and chromogen application: The following morning the slides were rinsed with distilled water and placed in TBS for 5 minutes. The secondary antibody, biotinylated anti-rabbit immunoglobulins (LSAB2 KIT, Dako, Carpinteria, CA) was dropped on the slides, and the slides were incubated for thirty minutes at room temperature in the humidity chamber. The slides were rinsed with distilled water and placed in TBS for 5 minutes at room temperature. For labeling, streptavidin peroxidase (LSAB2 Kit, Dako, Carpinteria, CA) was dropped on the slides for thirty minutes at room temperature. After rinsing in distilled water and incubating for 5 minutes in TBS, the chromogen, 3-Amino-9-ethylcarbazole (AEC) (Dako, Carpinteria, CA) was applied for 15 minutes at room temperature. These procedures were done according to the directions from the manufacturer, Dako (Carpinteria, CA).

Counterstaining and coverslipping: The slides were rinsed in distilled water and counterstained with Aqueous Hematoxylin (Biomeda, Foster City, CA) for $1-2$ minutes. The slides were rinsed with tap water and covered with Crystal Mount (Biomeda, Foster City, CA) mounting media. The slides were allowed to completely dry before coverslipping with a coverglass and Permount (Fisher Scientific, Pittsburgh, PA). 
Slide Visualization and Morphology: Using an image analysis system (Image-1, Universal Imaging, West Chester, PA) the slides were morphologically quantified. From 8 to 10 small airways per slide, the number of positive CYP1A1 staining Clara cells per $\mathrm{mm}$ basement membrane were counted and recorded. Ten different frames of alveolar regions measuring $0.035 \mathrm{~mm}^{2}$ each were examined and the number of CYP1A1 positive plump epithelial cells were counted and recorded.

\section{9 - Enzymatic Immunohistochemistry for CYP2B1 (Experiment 1)}

The same procedure as previously described for CYP1A1 was used for CYP2B1 immunohistochemistry except for the use of a different primary antibody with a different dilution and incubation time. The primary antibody (rabbit anti-rat CYP2B1, Amersham, Buckinghamshire, England) was reconstituted with $300 \mu 1$ of 1\% BSA/PBS. The primary antibody was then diluted 1:10 with diluent (Dako, Carpentira, CA) and dropped on the slides. The slides were incubated overnight at $4{ }^{\circ} \mathrm{C}$ in the humidity chamber. Non-immune rabbit serum was applied to selected slides as a negative control. Image analysis was also performed as described above.

\section{0 - Immunofluorescence Staining for CYP1A1/Cytokeratin 8 (Experiment 2)}

Dual immunofluorescence for CYP1A1 and cytokeratin 8 was performed on the lung tissue to further define the location of CYP1A1 in the alveolus during silicosis and xenobiotic (BNF) exposure. Cytokeratin 8, is an intermediate filament which is part of the cytoskeleton in alveolar epithelium of the rat (Schlage et al, 1998). Cytokeratin 8 expression is generally weak in alveolar type I cells when compared to alveolar type II cell expression and was used to identify type II cells within the pulmonary alveolus. 
Preparation of slides for reacting with primary anitbodies: Slides were heated in an oven at $65^{\circ} \mathrm{C}$ for 20 minutes prior to deparaffinization. For deparaffinizing, slides were placed in 3 separate xylene baths for 6 minutes each, followed by 3 minutes in each of the following: $100 \%$ alcohol, $95 \%$ alcohol, and $80 \%$ alcohol. These were followed by a 5 minute bath in distilled water. To increase antigenicity, we modified a method of microwave antigen retrieval (Shi et al, 1991). A 0.01M EDTA solution ( $\mathrm{pH}$ 8.0), was prepared and used for microwave antigen retrieval. The slides were placed in a microwave safe plastic staining rack and container that was filled with the EDTA solution. The container was placed in the microwave (Kenmore \# 89626, Sears Roebuck and Co, Chicago, IL) and heated for 1 minute 45 seconds on high to bring the solution to just under $100^{\circ} \mathrm{C}$. The defrost cycle on the microwave was set for 6 minutes to keep the solution at a temperature just under boiling. After 6 minutes, additional EDTA solution was added to fill the container and the defrost cycle was repeated for 6 minutes. After microwaving, the solution was removed from the microwave and the slides remained in the hot solution for 20 minutes. The slides were then rinsed in distilled water and placed in a coplin jar with distilled water for 5 minutes. Unless otherwise specified, the remaining steps were performed in a humidity chamber to prevent the slides from drying. A 5\% solution of IgG-free BSA (Sigma Chemicals, St. Louis, MO) in PBS was applied to the slides as a block for 10 minutes at room temperature. The slides were rinsed with distilled water and 5\% pig serum in PBS (Biomeda, Foster City, CA) was applied for 10 minutes at room temperature. 
Reaction of lung tissue with primary antibodies:

The first primary antibody, sheep anti-human cytokeratin 8 (The Binding Site, Birmingham, United Kingdom, England) was diluted 1:10 with Dako Diluent. The second primary antibody, rabbit anti-rat CYP1A1 (Xenotech, Kansas City, KS) was diluted 1:5 with the 1:10 diluted cytokeratin 8 to produce a suspension containing a 1:5 CYP1A1 and 1:10 cytokeratin 8 antibody solutions. Using capillary action, the suspension containing both primary antibodies was applied to the slides. The slides were incubated overnight at room temperature then placed in an oven at $37^{\circ} \mathrm{C}$ the following morning for 2 hours. The slides were then rinsed thoroughly with distilled water. Rinsing the slides consisted of a 5 minute bath in a coplin jar with distilled water repeated 3 times.

The secondary antibodies, Alexa 594 goat anti-rabbit IgG super highly cross absorbed, and Alexa 488 donkey anti-sheep IgG, (Molecular Probes, Eugene, OR) were diluted 1: 20 with PBS, vortexed, and centrifuged for 5 minutes. The supernatant from each secondary was applied to each slide for 2 hours at room temperature and kept in a dark environment. The slides were then rinsed very well with distilled water as described previously and coverslipped with a glass coverslip and GelMount (Biomeda, Foster City, CA). The slides were stored in the dark and refrigerated until analyzed. Visualizing the sites of CYP1A1 and Cytokeratin 8 expression:

Using a Quantix Digital Camera (Photometrics, Tucson, AZ) and an Olympus AX70 photomicroscope (Olympus, Melville, NY), images were captured as bitmap files. CYP1A1 expression was visualized as red fluorescence using a Texas Red cube with an excitation at $460-500 \mathrm{~nm}$ and bandpass emission of 510 - $560 \mathrm{~nm}$ (U-M41004 HQ-TR, 
Olympus, Melville, NY). Cytokeratin 8 expression was visualized as green fluorescence using a band pass FITC cube with an excitation at 432.5 - $487.5 \mathrm{~nm}$ and bandpass emission of 607.5 - $682.5 \mathrm{~nm}$ (41001 HQ-FITC, Olympus, Melville, NY). Five images each of both proximal alveolar regions near terminal bronchi, and random, alveolar regions between visible terminal bronchi were captured as 1024 x 1024 pixel arrays and saved as 12.2 MB bitmap files. Each image was taken using the green cube, red cube, and combined image.

\section{1 - Quantification of CYP1A1 and Cytokeratin 8 IF staining in Alveoli}

\section{(Experiment 2)}

Each slide had two regions of interest - the proximal alveolar region (area adjacent to the terminal bronchioles, Figure 1A) and the random alveolar region (area between visible terminal bronchioles, Figure 1B). Photos with vascular endothelium from large vessels were avoided for both regions. From each slide, 5 images $(14,527.68$ micrometers ${ }^{2}$ ) were captured from each region using an Olympus AX70 Microscope (Melville, NY) with fluorescence capabilitiies, a $60 \mathrm{x}$ objective, and a digital camera (Quantix, Photometrix, Tuscon, AZ). The settings for brighteness, contrast, and gamma were held constant for each image.

Every image was captured and saved on a $\mathrm{CD}$ as red, green, and combined red and green image. Each image was then anaylzed by commercial morphometry equipment (Metamorph, Universal Imaging, West Chester, PA). The average from each of the 5 images was calculated for each rat. 
The following measurements were made on each region:

1) Percent of the region that fluoresced red

2) Area within the region that fluoresced red

3) Percent of the region that fluoresced green

4) Area within the region that fluoresced green, and

5) Area of the region that fluoresced both red and green

Red fluorescence indicated sites of CYP1A1 expression. Green fluorescence indicated sites of cytokeratin 8 expression, which was primarily in airway epithelial cells in the airways and alveolar type II cells in alveoli.

The formulas are defined as follows:

The percent CYP1A1 and cytokeratin 8 and the area of CYP1A1 and cytokeratin 8 are values directly measured by Metamorph software.

Area of CYP1A1 expressed in non-cytokeratin 8 areas (non type II cells) $=$ percent of CYP1A1 not in Cytokeratin 8 areas (directly measured by Metamorph software) X total area of CYP1A1 in image (measured directly by Metamorph software, in square microns).

Area of CYP1A1 expressed in Cytokeratin 8 areas (alveolar type II cells) $=$ percent of CYP1A1 in Cytokeratin 8 areas (directly measured by Metamorph software) $\mathrm{X}$ total area of CYP1A1 in image (measured directly by Metamorph software, in square microns).

Proportional expression of CYP1A1 in alveolar type II cells = percent of CYP1A1 in Cytokeratin 8 areas (directly measured by Metamorph software) $\mathrm{X}$ total area of CYP1A1 expression in image (measured directly by Metamorph software, in 
square microns) / Total area of cytokeratin 8 expression in image (measured directly by

Metamorph, in square microns).
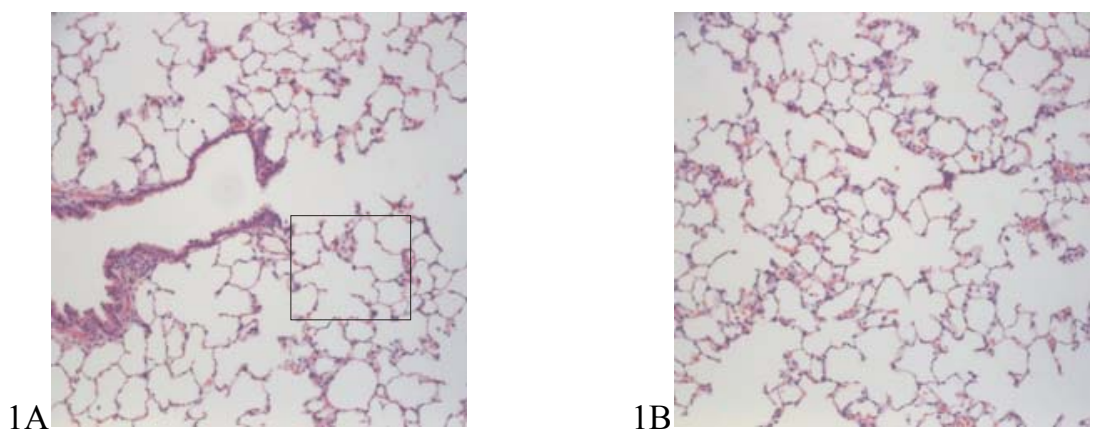

Figure 1 Sampling of pulmonary alveoli by digiatl image capture.

1A . A representative sample digitally captured and analyzed for Proximal Alveolar Regions. Care was taken not to include open airway or any part of the terminal bronchus. 1B. The Random Alveolar Regions are areas between and away from visible terminal bronchioles. Care was taken to get areas from separate areas of the slides and between airways.
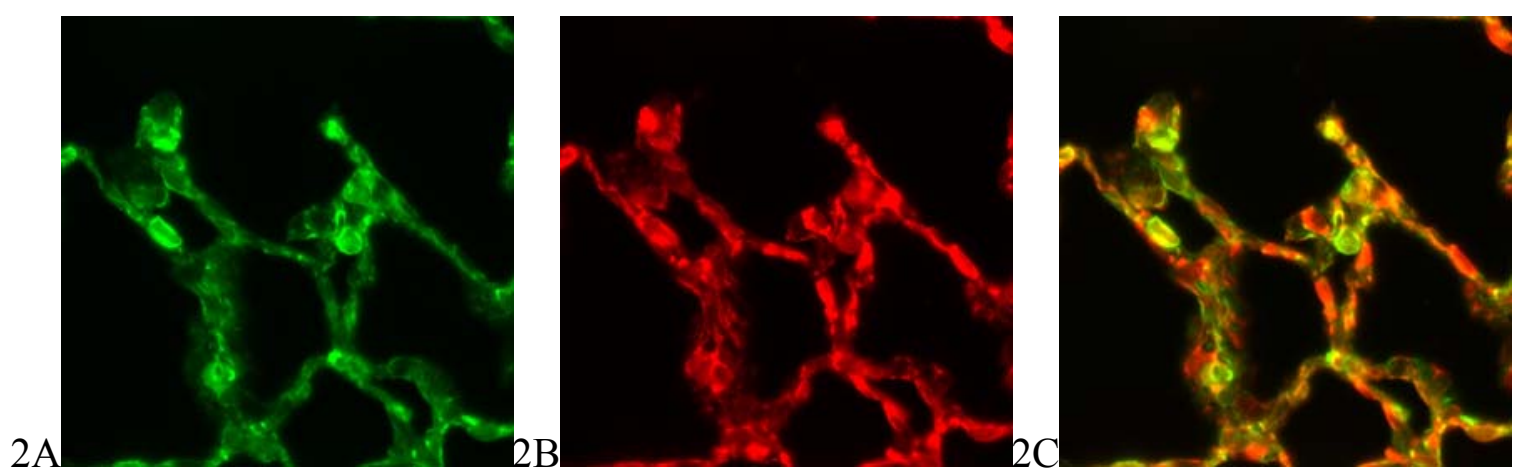

Figure 2 . Example of Double-Immunofluorescence Staining. The bright green staining in A represents Cytokeratin 8 positive cells. The bright red staining represents CYP1A1 positive cells. $\mathrm{C}$ is a combined (colocalized) image of cytokeratin 8 and CYP1A1 immunofluorescence. Yellow staining represents areas that are both CYP1A1 and Cytokeratin 8 positive.

\section{$\underline{22}$ - Statistical Analysis(Experiments 1,2 and 3)}

All analysis was performed using SAS Version 8.2. Data from the first experiment was analyzed as a Three Way Analysis of Variance (ANOVA) comparing IT exposure, CYP1A1 inducer, and CYP2B1 inducer. Pairwise comparisons were done 
using Fishers Least Significant Difference test (LSD). The second experiment was analyzed as a Two Way Anova comparing IT exposure and inducer effects. Pairwise comparison tests were also done using Fishers LSD. A One Way Anova was used to compare the IT exposures in the third experiment. Histopathology scores were analyzed non-parametrically by the Kruskal-Wallis test. For all data, values of $\mathrm{P}<0.05$ were defined as statistically different. 


\section{Chapter 4}

\section{Results}

\section{1 - Histopathology - Light Microscopy findings in silica-exposed rats}

During experimental silicosis, rats developed significant accumulations of lipoprotein within alveolar spaces two weeks after instillation. Alveolar type II cells, which produce lipoprotein, were also hypertrophied and hyperplastic. These changes were accompanied by inflammation. Alveolar lipoproteinosis, alveolar type II cell hyperplasia, and alveolar inflammation were seen in all silica exposed rats but were not seen in any saline-instilled control rats.

The morphologic changes observed in the lungs and lymph nodes in the third experiment were converted to quantitative scores and analyzed statistically. The following morphological changes in the lung: alveolitis $(p=0.0123)$, lipoproteinosis $(p=$ 0.0008), and type II cell hypertrophy and hyperplasia $(\mathrm{p}=0.0069)$, were significantly associated with silica exposure. Inflammation in the tracheobronchial and parathymic lymph nodes was also significantly associated with silica exposure. A dose response relationship was not observed among the silica exposed groups (Table R1).

Table R1 Pathology Scores from Dose Response Experiment (Experiment 3) $)^{1,2}$

\begin{tabular}{|l|l|l|l|}
\hline Group & Lipoproteinosis & $\begin{array}{l}\text { Type II Cell } \\
\text { Hyperplasia and } \\
\text { Hypertrophy }\end{array}$ & Alveolitis \\
\hline NF and Saline & $0(0)$ & $0(0)$ & $0(0)$ \\
\hline NF and 5 mg Silica & $5(4-6)$ & $6(4-6)$ & $6(5-7)$ \\
\hline NF and 10 mg Silica & $5(4-6)$ & $6(6-6)$ & $6(5-7)$ \\
\hline NF and 20 mg Silica & $5(5-5)$ & $6(6-6)$ & $6(6-7)$ \\
\hline
\end{tabular}

1. Pathology score is the sum of the severity (the degree of change) and the distribution (the extent of change) scores.

2. Score is given as median (range) 


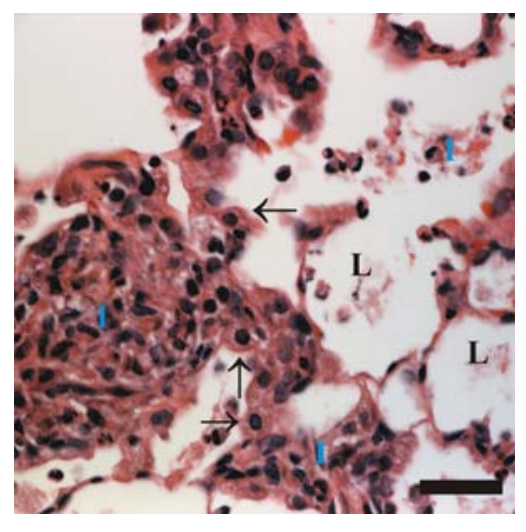

Figure 3 Example of silicotic rat lung. Morphologic changes include lipoproteinosis (L), type II cell hyperplasia (arrows), and inflammation (I) which is manifested as alveolitis. Bar equals 30 microns.

\section{$\underline{2 \text { - Endotoxin Analysis }}$}

Representative samples of the sterilized silica and the saline solution were analyzed for endotoxin and all endotoxin concentrations were found to be under 0.2 $\mathrm{ng} / \mathrm{ml}$.

\section{$\underline{3 \text { - Experiment } 1 \text {-- Exposures to Classical Inducers of CYP Isoforms: The effect of }}$}

\section{inducers of cytochrome P450 on pulmonary CYP2B1 immunohistochemistry in}

\section{$\underline{\text { silicosis }}$}

Exposing control and silica-exposed rats to the hepatic CYP2B1 inducer, phenobarbital (PB, $100 \mathrm{mg} / \mathrm{kg}$, IP, twice) did not affect the airway and alveolar distribution of CYP2B1. Similarly, exposing control and silica-exposed rats to the pulmonary CYP1A1-inducer, ß-naphthoflavone (NF, $50 \mathrm{mg} / \mathrm{kg}$ once, IP, once, 3 days prior to necropsy), did not alter the airway and alveolar distribution of CYP2B1. Exposing control and silica-exposed rats to both PB and NF (50 mg/kg NF once, 100 $\mathrm{mg} / \mathrm{kg}$ PB twice) also did not affect the airway and alveolar distribution of CYP2B1. In particular, the hypertrophied alveolar type II cells of silicosis remained devoid of immunohistochemically detectable CYP2B1. The number of morphometrically 
measurable CYP2B1 expressing cells was unaffected by silica, NF, PB, or combinations of these exposures (Figure 4).
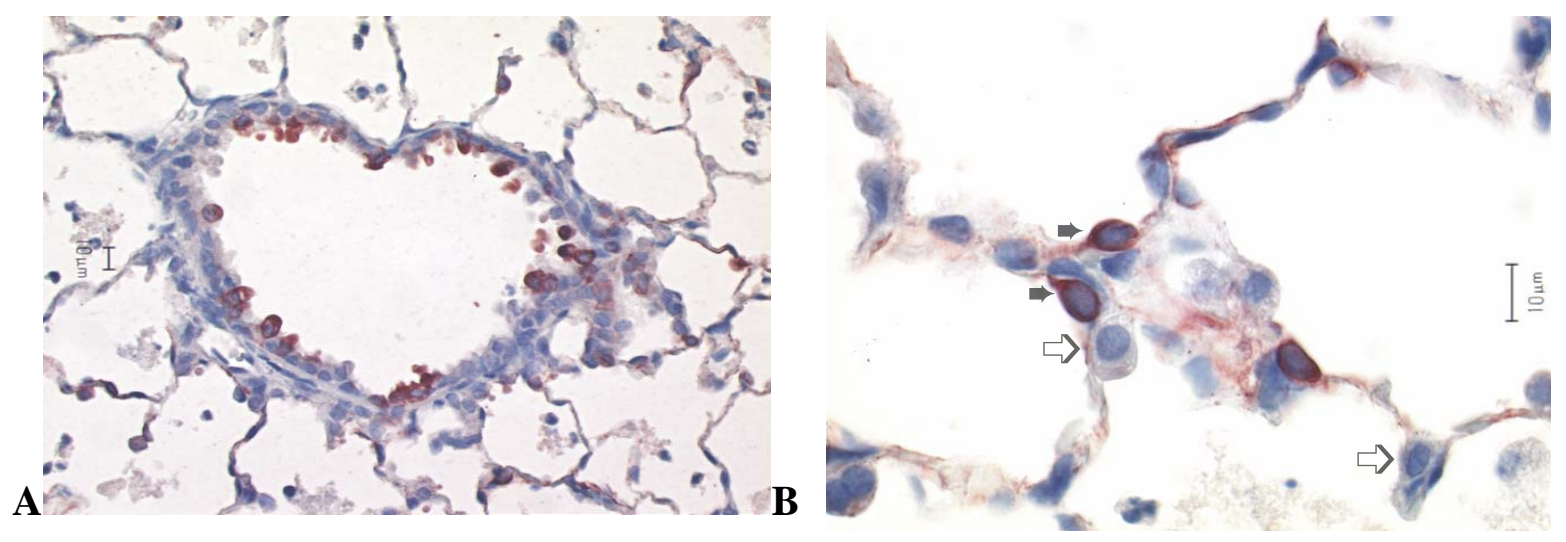

Figure 4. CYP2B1 Immunohistochemistry A. Positive non-ciliated airway epithelial cells were found in all groups. B. Positive cuboidal alveolar epithelial cells $(\vec{b})$ were also found in all groups. Cuboidal alveolar cells without immunoreactivity $(\square)$ were also found in the silica exposed animals.

\section{A - The effect of inducers of cytochrome P450 on pulmonary CYP1A1}

\section{immunohistochemistry in silicosis}

CYP1A1 was consistently detected in the lungs of all rats receiving the CYP1A inducer, NF. No immunohistochemical evidence of CYP1A1 was seen in rats that did not receive NF. NF consistently resulted in the appearance of immunohistochemically detectable CYP1A1 in alveoli and airways. In airways, NF exposure resulted in CYP1A1 expression in nonciliated airway epithelial cells. In the vasculature, NF exposure resulted in CYP1A1 expression in endothelial cells. In the alveolus, the thin cytoplasm of alveolar type I cells appeared to contain immunoreactive CYP1A1, although reactivity of capillary endothelial cells could not be excluded. Some alveolar lining cells with the morphologic appearance of alveolar type II cells contained CYP1A1. However, the hypertrophied alveolar type II cells which are characteristic of silicosis did not express 
immunohistochemically detectable CYP1A1. Morphometry indirectly showed that silicosis did not significantly affect the number of airway or cuboidal alveolar epithelial cells (presumptive alveolar type II cells) expressing CYP1A1 after NF exposure (Figure 5). Due to the thin cytoplasm of alveolar type 1 cells and alveolar capillary endothelial cells, the number of these cells expressing CYP1A1 could not be counted by morphometric analysis of immunohistochemically stained sections. PB, an inducer of hepatic CYP2B1, had no effect on pulmonary CYP1A1 expression.
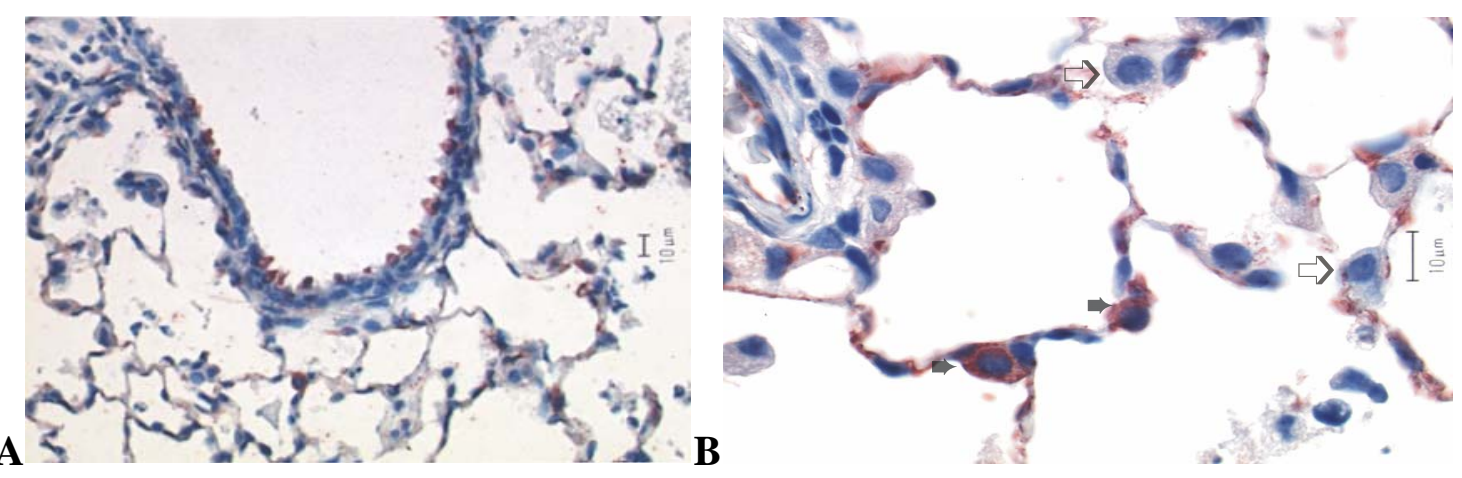

C

CYP1A1 positive alveolar cells per field

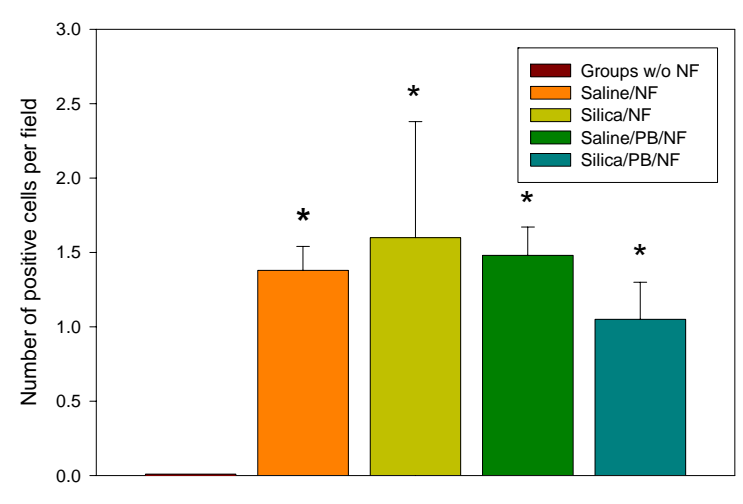

Figure 5. A. Positive non-ciliated airway epithelial cells were only found in groups exposed to $\beta$-naphthoflavone. B. Positive plump alveolar epithelial cells $(\vec{b})$ were also found only in groups exposed to $\beta$-naphthoflavone. Plump alveolar cells without immunoreactivity $(\square)$ were also found in silica exposed animals. C. CYP1A1 positive cells were present after $\beta$-naphthoflavone exposure and the number of cells was not significantly increased by phenobarbital or silica. *Significantly different from all groups that did not receive NF $(p<0.05)$. 


\section{B - The effect of silicosis on induction of CYP-dependent enzymatic activity}

Both ECOD (CYP-dependent) and EROD (CYP1A1-dependent) activities were significantly increased by NF exposure $(\mathrm{p}<0.0001)$. The induction of EROD and ECOD activity by BNF was significantly inhibited by prior intratracheal administration of silica (Figure 6).

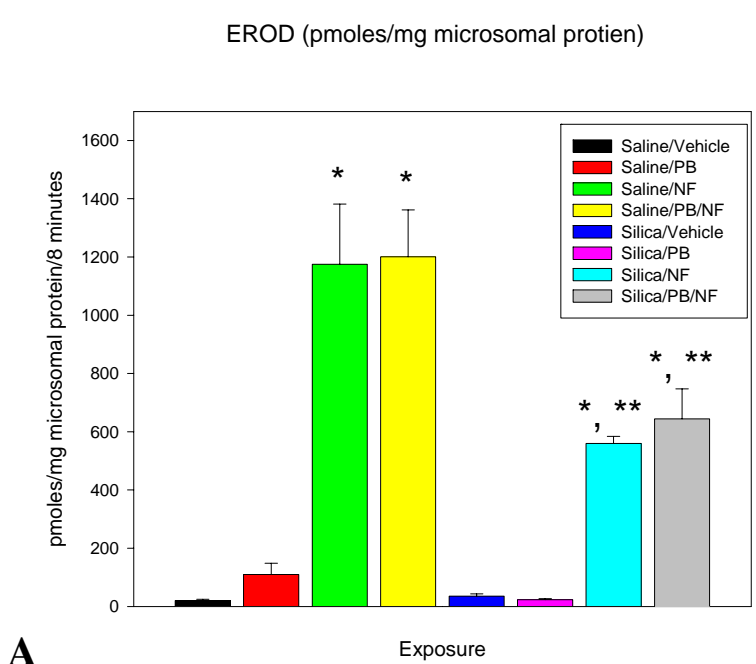

A

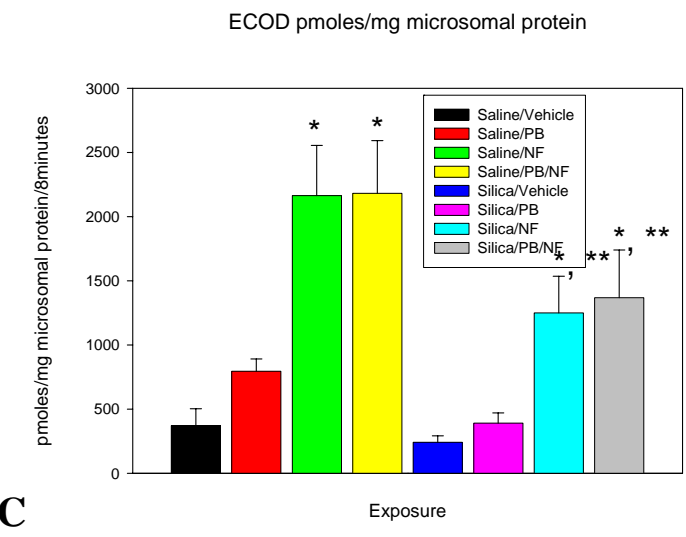

Figure 6 A and B. The effect of silica exposure on EROD and ECOD activity in BNF or PB exposed rats. EROD activity was significantly increased in all animals exposed to NF. There was significantly less EROD activity in animals treated with Silica/NF or Silica/NF/PB compared with Saline/NF and Saline/PB/NF . *Significantly different from all groups without NF $(\mathrm{p}<0.05)$. ** Significant decrease from Saline/NF and Saline/NF/PB treatment groups $(\mathrm{p}<$ $0.05)$. C. ECOD products after 30 minutes of incubation showed a significant increase in animals treated with NF $(\mathrm{p}<0.0001)$. Animals also treated with silica had significantly less activity than NF exposed control animals $(\mathrm{p}=0.0033)$. 


\section{A - Experiment 2: The effect of silicosis on localized expression of CYP1A1 and}

\section{Cytokeratin 8 in the pulmonary alveolus of BNF exposed rats}

Two distinct areas of the lung were analyzed, the proximal alveolar region (PAR) and the random alveolar region (RAR). The proximal alveolar region is the area immediately adjacent to the terminal bronchi and the random areas are sampled as alveolar regions between visible terminal bronchi. In both the RAR and PAR alveolar regions, CYP1A1 was not observed in the lungs of control rats and intense red fluorescence consistent with induction of CYP1A1 was seen in all rats receiving i.p. NF. Both control and silica-treated rats had plump, cuboidal cells that were morphologically consistent with alveolar type II cells and fluoresced green, indicating cytokeratin 8 expression.

The Proximal Alveolar Region:

Cytokeratin 8 was expressed in all groups. However, expression was significantly increased in groups exposed to silica. CYP1A1 was only detected in animals exposed to NF (Figures 7 and 8). The amount of CYP1A1 expressed in type II cells was not found to be significantly different between saline and silica groups treated with NF. The proportional expression of CYP1A1 in type II cells (the amount of CYP1A1 expressed in type II cells corrected for increases in type II cell number) was found to be significantly reduced in rats exposed to both NF and silica compared to NF-exposed rats without silicosis (Figures 7 and 8). 


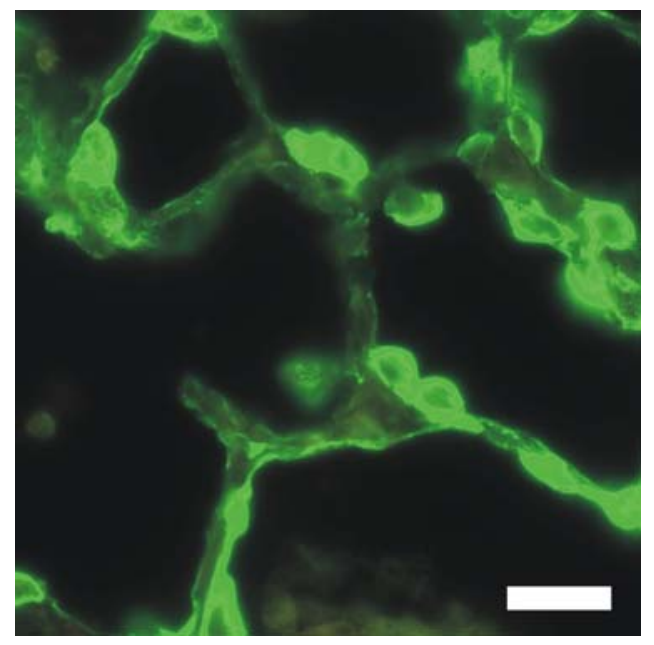

A. Silica/Corn oil

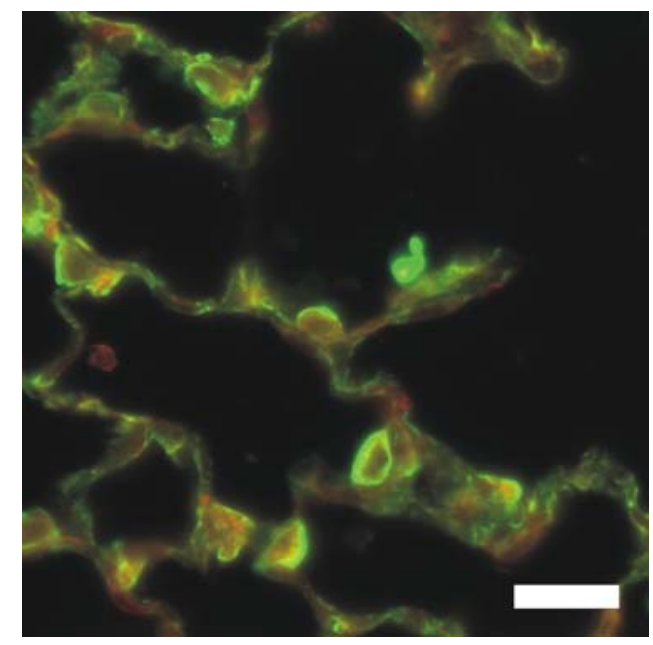

C. Saline/Corn Oil

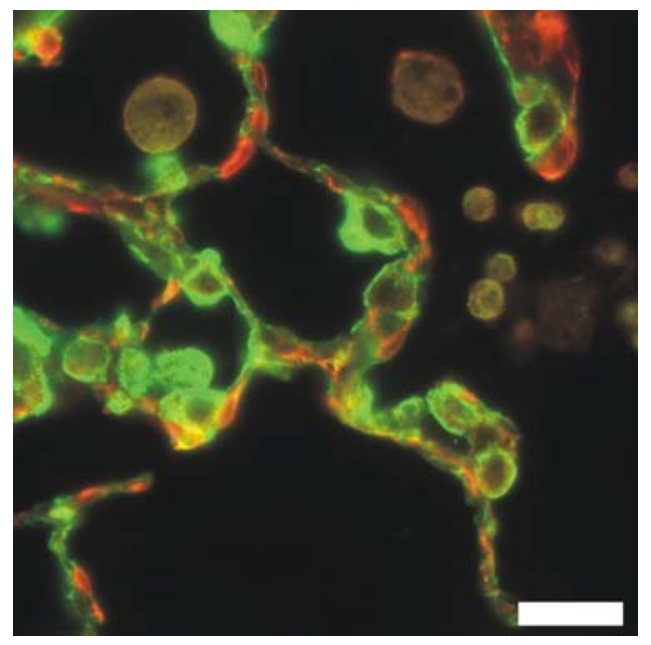

B. Silica/NF

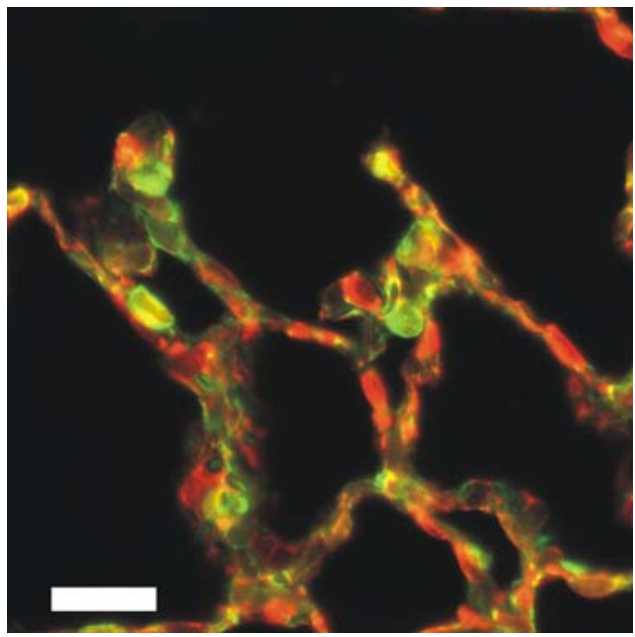

D. Saline/NF

Figure 7 Immunofluorescenct localization of CYP1A1 and Cytokertin 8 in Proximal Alvelor Regions. Animals that did not receive NF, did not express any detectible CYP1A1. A. In silica/corn oil exposed animal, many plump, cuboidal, cytokeratin 8 positive(green), alveolar type II cells are found. B. In silica/NF exposed animals, notice the plump, cuboidal, cytokeratin 8 positive cells(green) are abundant, while long, thin, alveolar cells are CYP1A1(red) positive. Yellow staining represents cells expressing both cytokeratin 8 and CYP1A1. C. A saline/corn oil exposed animal has far less cytokeratin 8 positive (green) cells, and these cells are not as hypertrophied. In addition, CYP1A1 expression is not observed. D. In a saline/NF exposed animal, there are again far fewer and smaller cytokeratin 8 positive cells, and CYP1A1 expression is localized in the thin, long alveolar cells. Notice that there are more CYP1A1 positive cells in the septum of saline and NF exposed animal than the silica and NF exposed animal. 
Proximal Alveolar Regions

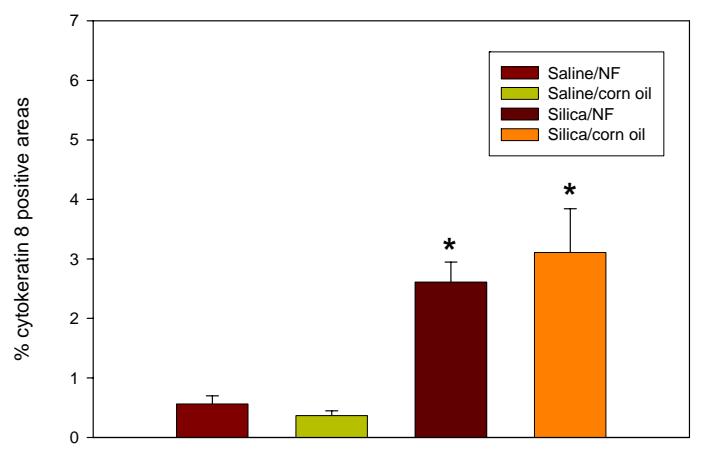

A

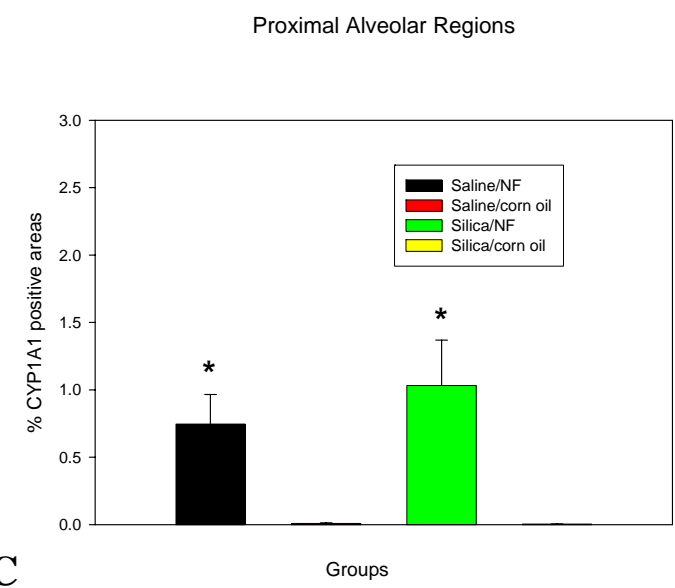

Proximal Alveolar Regions

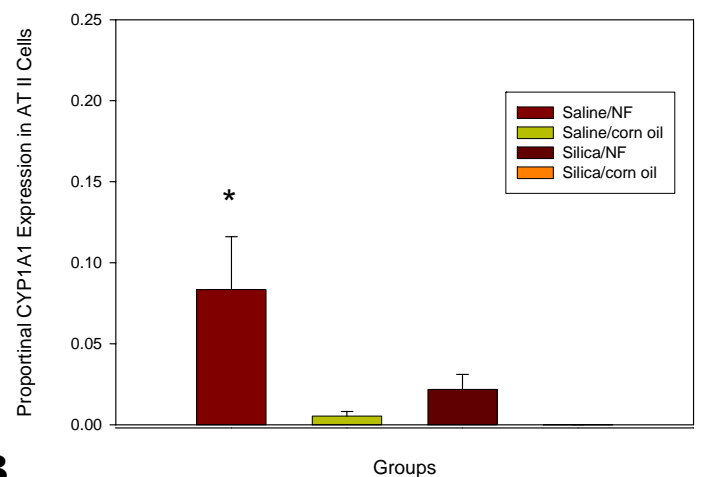

Figure 8 Proximal Alveolar Regions - A. The area of alveolus containing cytokeratin 8 expressing cells was significantly increase by silica exposure $(\mathrm{p}=0.0003)$. * significantly different from saline groups. B. The proportional CYP1A1 expression in type II cells was found to have significantly less expression in silica/NF treated animals compared to saline/NF treated animals $(\mathrm{p}=0.0082)$ * Significantly different compared to groups without NF and the silica/NF group. C. As expected, only animals receiving NF were positive for CYP1A1 $(\mathrm{p}<$ $0.0001)$. * Significantly different compared to groups not receiving NF.

\section{$\underline{\text { Random alveolar region: }}$}

CYP1A1 expression was consistently observed in NF exposed animals.

Cytokeratin 8 was expressed in all groups but there was not a significant difference in expression between groups. As in the proximal alveolar region groups, there was not a significant difference in the area of CYP1A1 expressed in either type II cells or non type II cells. The proportional expression of CYP1A1 in type II cells was decreased in silica/bnf treated groups compared with saline/nf groups, but this difference was not statistically significant (Figures 9 and 10). 


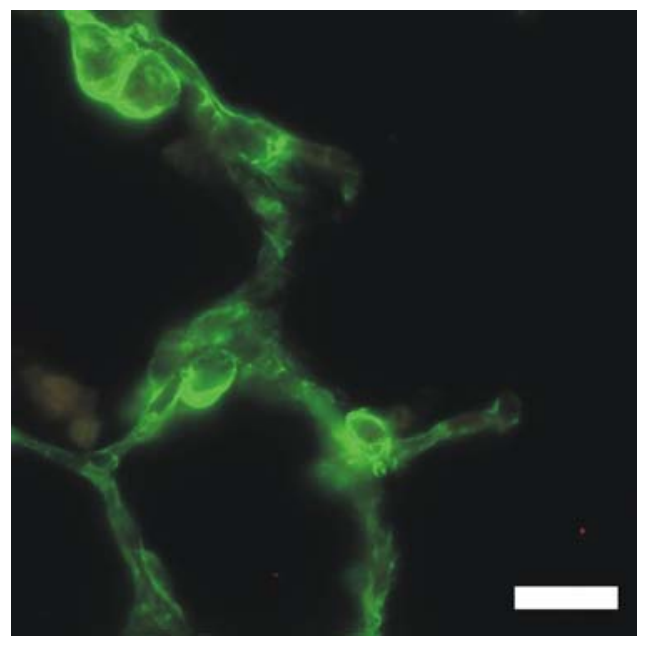

A. Silica/Corn Oil

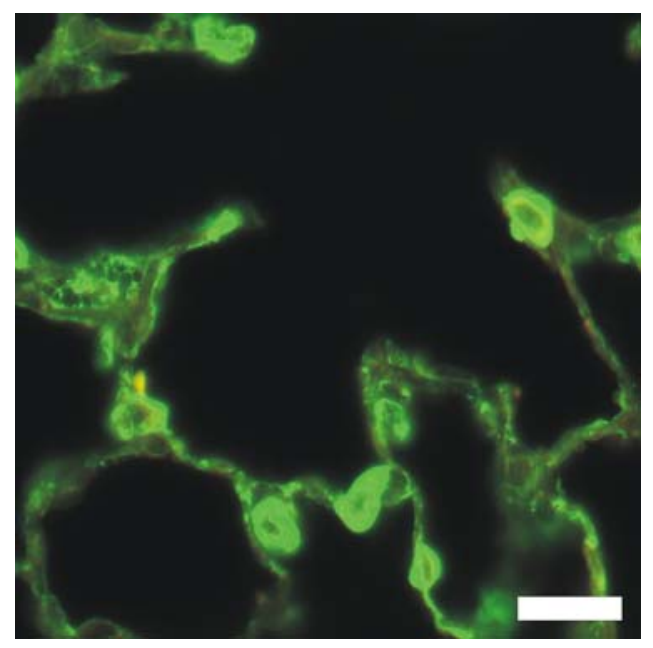

C. Saline/Corn Oil

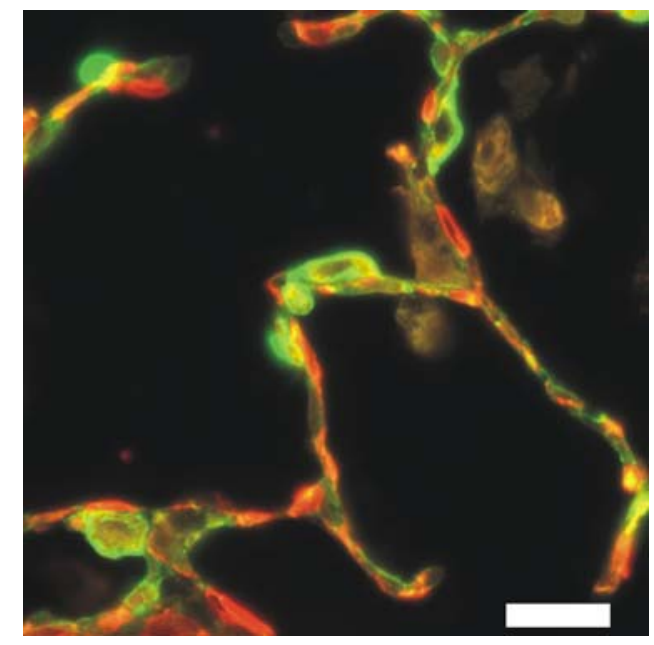

B. Silica/NF

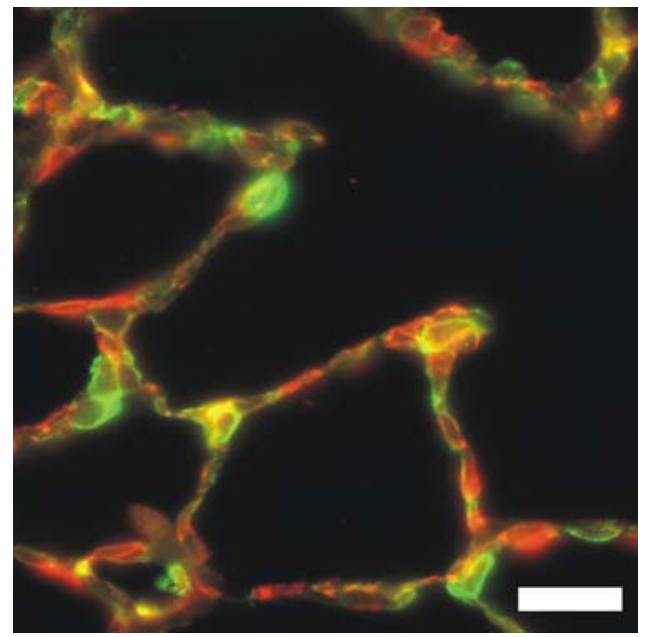

D. Saline/NF

Figure 9 Immunofluorescent localization of CYP1A1 and cytokeratin 8 in Random Alveolar Regions. Animals exposed only to saline (A) had comparable expression of cytokeratin 8 in the random alveolar regions as compared with silica exposed animals (C). Animals that did not receive NF did not express CYP1A1. Animals exposed to NF and either saline (B) or silica (D) expressed CYP1A1, but expression was not significantly different in the random alveolar regions. 
Random Alveolar Regions

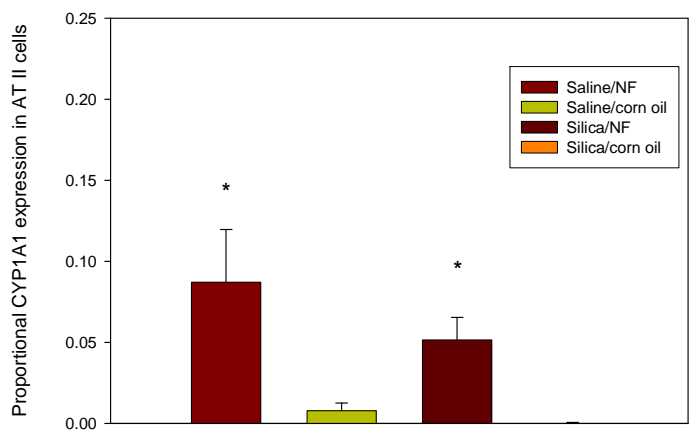

A

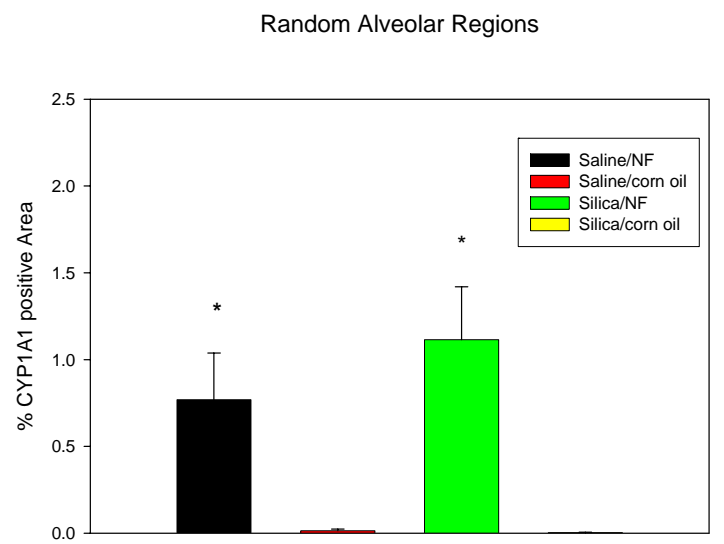

C

Groups
Random Alveolar Regions

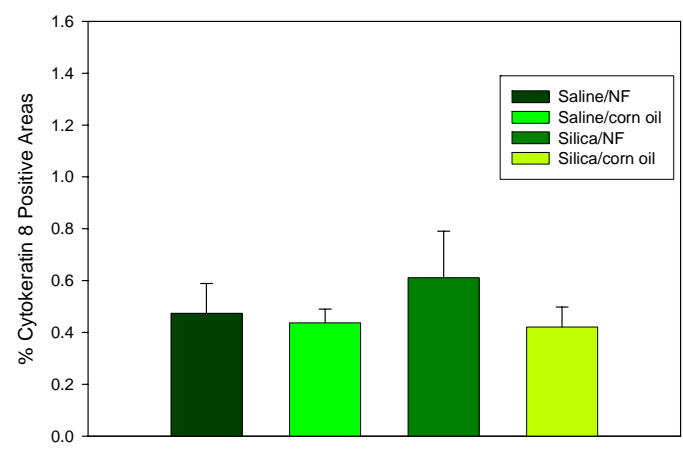

B

Groups
Figure 10 Random Alveolar Regions - A. The proportional CYP1A1 expression in type II cells is lower in silica/nf treated animals when compared to silica/corn oil animals. However it is not significantly lower $(\mathrm{p}=0.4388)$.

* Significantly different from groups without NF. B. Cytokeratin 8 expression is not significantly different among any of the groups in the random alveolar regions $(\mathrm{p}=0.6075)$.

C. CYP1A1 expression is primarily expressed in NF exposed rats and is not significantly different between the silica and saline groups $(\mathrm{p}=0.3934) . \quad)$ * Significantly different from groups without NF.

\section{$\underline{\text { 4B - The effect of silicosis on induction of CYP1A1 and CYP2B1-dependent }}$}

\section{enzymatic activity}

CYP1A1 dependent EROD activity was significantly increased in groups that received NF. There was also a significant decrease in EROD activity of silica/NF groups compared to saline/NF groups. PROD (CYP2B1 dependent) activity was also found to be significantly lower in groups exposed to silica when compare to saline groups. NF treatment did not have a significant effect on PROD activity (Figure 11). 
EROD (protein)

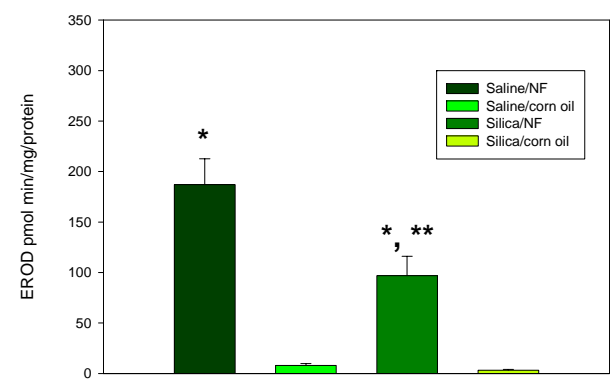

A

Groups
PROD(Protein)

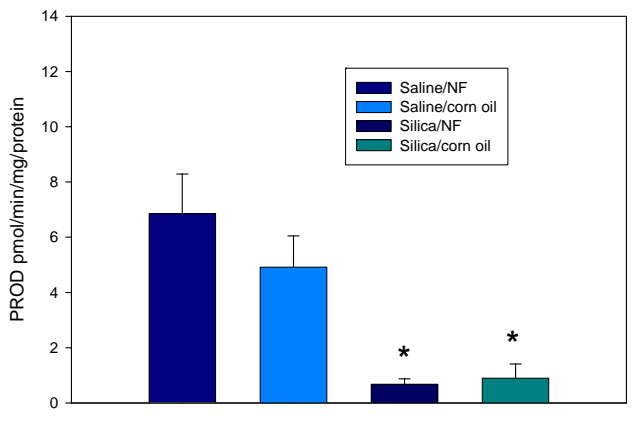

B

Groups

Figure 11 A. EROD (CYP1A1 dependent) activity is significantly increased in groups that received $\mathrm{NF}\left({ }^{*}\right)(\mathrm{p}<0.0001)$, and there is a significant decrease in activity in CYP1A1 induction by NF in silicotic rats $(* *)(\mathrm{p}=0.0153)$ groups compared to saline/nf groups. B. Groups receiving silica had significantly less PROD (CYP2B1) activity than groups than saline groups $(\mathrm{p}<0.0001)$. NF did not have a significant effect on PROD activity.

\section{$\underline{\text { 4C - The effect of silicosis on CYP1A1 protein }}$}

Western blot analysis was performed for CYP1A1. As with immunofluorescence, groups that did not receive NF, did not express detectable CYP1A1 protein. For groups receiving $\mathrm{NF}$, the $\%$ of positive control was significantly less in silica groups compared to saline groups (Figure 12).

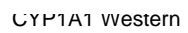

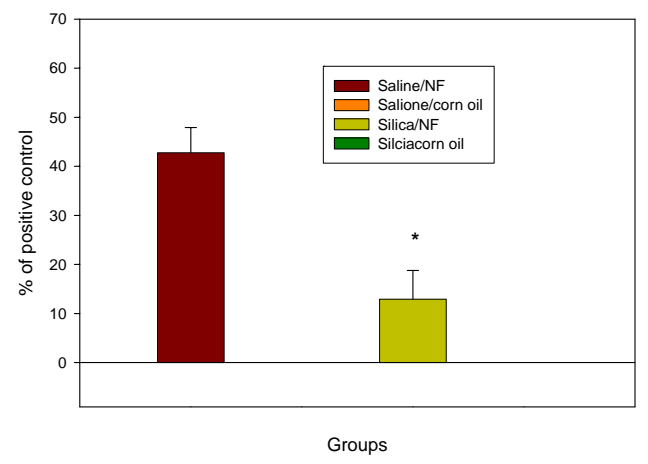

Figure 12 Western Blot analysis of CYP1A1. CYP1A1 was only detected in groups that received BNF. When expressed as percent of positive control, there was significantly less protein expressing in silica/nf groups than saline/nf groups $\left(^{*}\right)(\mathrm{p}=0.0009)$. 


\section{5 - Experiment 3:Silica Dose Response Study with Exposure to Classical Inducer of}

\section{CYP1A1: The effect of silicosis on induction of CYP1A1 and CYP2B1-dependent}

\section{enzymatic activity}

BNF induced CYP1A1 dependent activity (EROD) was significantly lower in all silica exposed groups compared to the saline group. There were no significant differences between silica exposed groups. CYP2B1- dependent PROD activity also showed significant decreases in activity of all silica groups compared to saline. There also was not a significant difference between the silica groups (Figure 13).

EROD (protein)

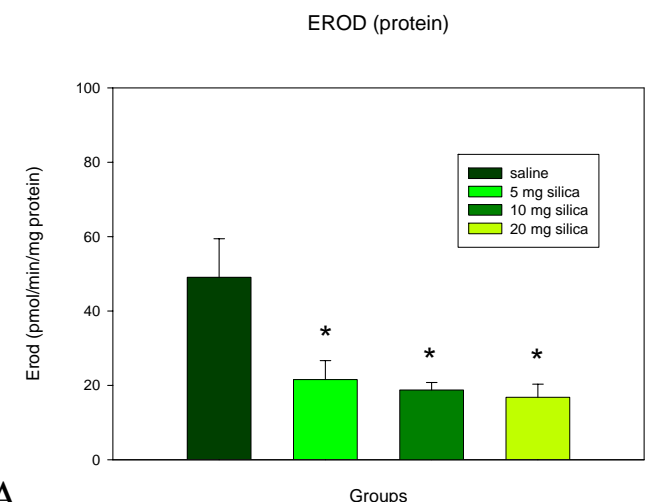

A

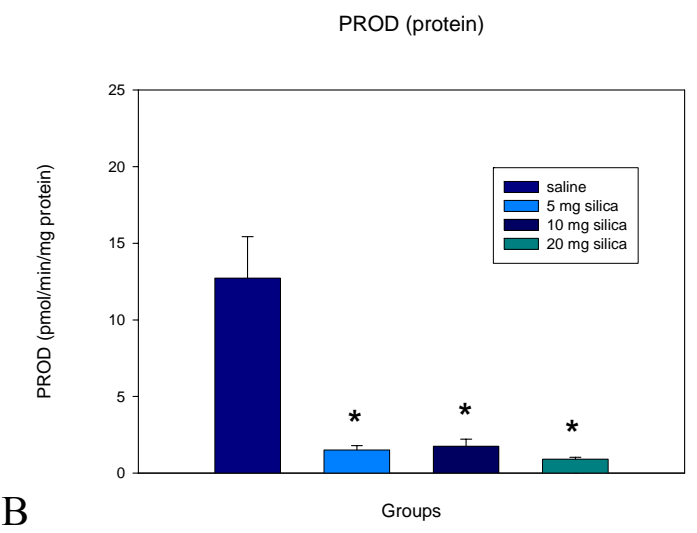

Figure 13 For both PROD (CYP2B1 dependent) and EROD (CYP1A1 dependent) activity was significantly lower in all BNF and silica exposed groups $(*)$ compared to the $\mathrm{BNF}$ and saline exposed group. (A. $\mathrm{p}<0.0001$, B. $\mathrm{p}=0.0035)$.

\section{A - The effect of silicosis on CYP1A1 and CYP2B1 proteins}

By western blot analysis, silica and BNF exposed groups have significantly less CYP1A1 protein than the BNF and saline exposed group. 
Western Blot analysis of CYP2B1 found all BNF and silica groups have significantly less CYP2B1 protein than the BNF and saline exposed group, but there were no significant differences amongst the silica treated groups(Figures 14 and 15).

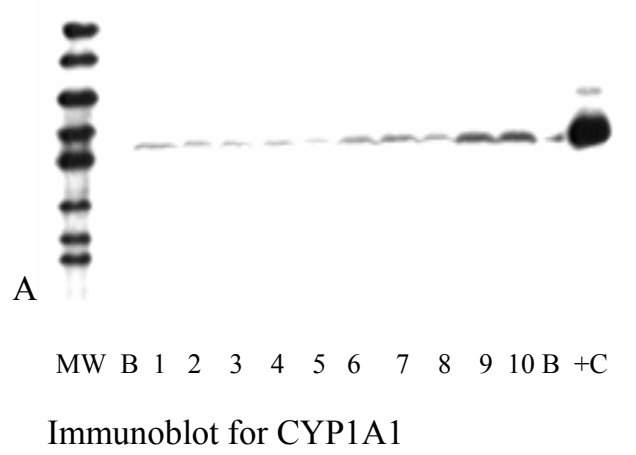

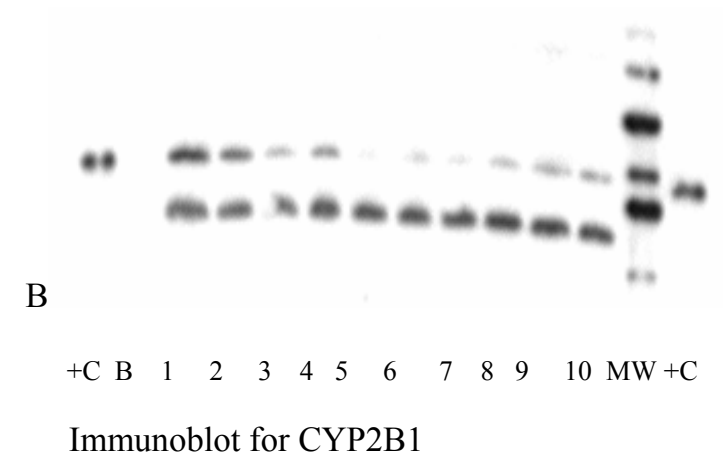

Figure 14 Lanes marked MW stand for Molecular Weight marker, B stands for blank, and $+\mathrm{C}$ stands for positive control (BNF treated rat liver microsomes for CYP1A1 and Phenobarbital treated liver microsomes for CYP2B1) For this experiment, all animals received NF. A is an Immunoblot for CYP1A1 - Lanes 1 and 2 were rat lung microsomes treated with $20 \mathrm{mg}$ silica, Lanes 3 and 4 received $10 \mathrm{mg}$ silica, lanes 5, 6, and 7 received, $5 \mathrm{mg}$ silica, and lanes 8,9 , and 10 received saline. $\mathrm{B}$ is an immunoblot for CYP2B1 - Lanes 1, 2, 3 received saline, lanes 4 and 5 received $5 \mathrm{mg}$ silica, lanes 6, 7, and 8 received $10 \mathrm{mg}$ silica, and lanes 9 and 10 received $20 \mathrm{mg}$ silica. In both blots, silica treated animals expressed less protein (CYP1A1 and CYP2B1) than saline treated rats. 
CYP1A1 Western Blot

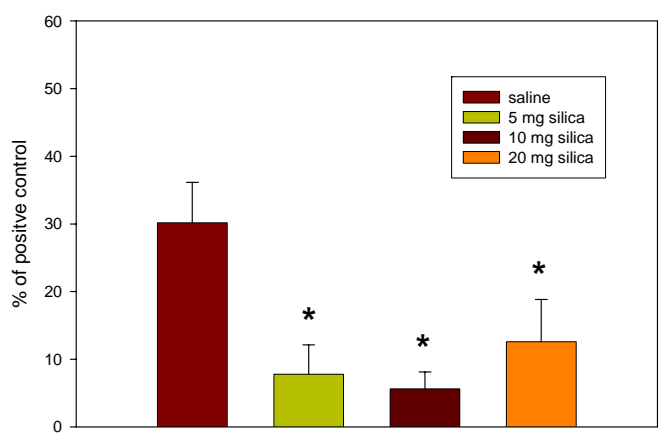

A

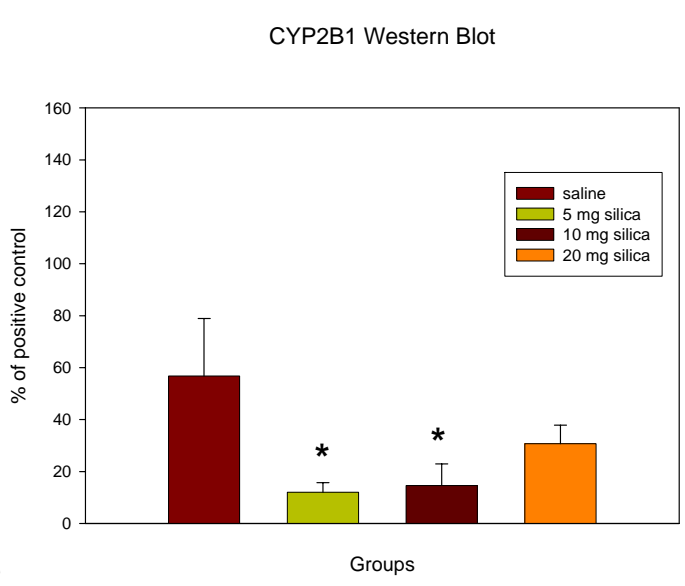

Figure 15 A. Graph quantifying western blots of CYP1A1 protein expression. BNF and silica exposed rats $(*)$ expressed significantly less CYP1A1 protein than rats exposed to BNF and the IT vehicle (saline) $(\mathrm{p}=0.0039)$. B. All BNF and silica exposed rat groups expressed less CYP2B1 protein than rats exposed to BNF and the IT vehicle (saline); however only doses of $5 \mathrm{mg}$ and $10 \mathrm{mg}$ (*) were significantly different. 


\section{Chapter 5}

\section{Discussion}

It is important to note that these experiments were carried out on animals exposed to $\beta$-naphthoflavone, a CYP1A1 inducer. EROD and ECOD activity in rats only exposed to saline or silica in the first experiment were found to be comparable with results from Miles et al, 1993 and 1994. EROD activity was increased in animals exposed to silica compared to saline. Levy et al, 1997 performed immunohistochemistry for CYP1A1 and CYP2B1 in the lungs of rats that were only exposed to silica or saline. Again, looking at only saline or silica exposed animals from our first experiment, our results were comparable. CYP1A1 was not detected in any animals not receiving NF and although CYP2B1 was detected, there was not a significant difference in the number of cells expressing CYP2B1 between the silica and saline exposed animals. Differences in CYP1A1 activity were only found when animals were exposed to CYP1A1 inducers with and without silica exposure. In NF-exposed rats, silica caused a decrease in CYP1A1 activity, CYP1A1 protein expression, and proportional expression in epithelial type II cells in animals exposed to silica and inducer.

In this study a technique a technique was developed for immunofluoresent labeling and quantifying of alveolar type II cells that was time efficient and allowed for ease of data quantification. Previous research on alveolar type II cell proliferation has been performed using electron microscopy techniques that were time consuming and costly and required special fixation (Miller and Hook, 1990). In 1987, Miller et al described a technique using alkaline phosphatase immunohistochemistry that was a vast 
improvement over electron microscopy. However, with this technique, fixation and the immunhistochemistry procedure must be carried out at $4^{\circ} \mathrm{C}$ to preserve enzyme activity (Miller, et al 1987). In the alveolar regions, only epithelial type II cells stained positively for alkaline phosphatase making them easy to recognize under a microscope. However, photomicrographs had to be taken and someone counted the number of positive cells. Although this was more cost efficient and less time consuming than electron microscopy, our method had advantages which included simplified tissue preservation, technical simplicity and rapid quantitative analysis. Using our method, the lungs could be fixed at room temperature with $10 \%$ neutral buffered formalin overnight and embedded in paraffin. They could be stored in paraffin for at least a year prior to analysis. Immunofluorescent staining was simple relative to alkaline phosphatase immunohistochemistry. Staining for cytokeratin 8 did not prevent subsequent staining with different fluoroprobes which permitted staining of 2 or more different antigens in a single tissue section. Using a fluorescent microscope with an attached digital capture allowed for instantaneous capture of the image. The instantaneous capture prevented the fluorescent fading which has long been a negative consideration with immunofluorescence (Johnson et al, 1982). The immunofluorescent images could then be saved onto a disk and the image could be analyzed by a morphometry program. Morphometry programs quickly quantified the amount of a fluoroprobe present in an image. Numerical area values for area of fluorochrome staining, and percent of the total area staining with a fluorochrome, and colocalization of multiple fluorochromes were easily determined and loaded into analytical programs. Using IF with quantitative morphometry, slides were rapidly analyzed for alveolar type II cell proliferation. In 
addition, we localized the expression of CYP1A1 in relation to the sites of cytokeratin 8 expression.

We demonstrated that the proximal alveolar region was the site of specific cell changes. We were able to show proliferation of alveolar type II cells in this region in response to silica exposure. We also were able to show that proportional CYP1A1 expression decreased in animals exposed to both silica and the NF inducer when compared to animals exposed to just NF. This was an important region to analyze as it was the site of particle deposition in intratracheally instilled rats (Brain et al, 1976). Inhalation methods of exposure resulted in deeper deposition of particles and may have produced different results. However, we were able to use our technique for detecting alveolar epithelial cell hypertrophy and hyperplasia and localizing CYP1A1 cellular expression and identified the site of particle deposition as the site where expression changed.

Smoking status is a critical factor in lung cancer development and should be a controlled variable in epidemiological studies of lung cancer involving other potential pulmonary carcinogens. However, one epidemiologic study suggested that people exposed to both silica and cigarette smoke had no difference in risk or even a reduced risk for lung cancer compared to people exposed to silica alone (Cocco, et al 1991). Many epidemiological studies either did not control, or inadequately controlled for cigarette smoke exposure. Pairon et al, 1991, reported that in some studies, smoking was not used as a variable at all. Although IARC added silica to its list of human carcinogens in 1997, some studies have not yet listed silica as a carcinogen (Tsuda et al, 2002) and some studies have disputed the carcinogen designation by IARC (Graham et 
al, 2004). Our studies showed that the model, PAH, NF was not a co-variable, but a modifier of lung cancer risk. Thus, it may be appropriate to analyze data from potential lung carcinogens both with control for cigarette smoking and with separate analyses for potential carcinogenesis in smokers and non-smokers.

In vivo and in vitro experiments have shown that inflammation decreases CYP1A1 activity (Tian et al, 1999; Ke et al, 2001; Paton and Renton, 1998) and inflammation was produced by silica exposure (Porter et al, 2001; Driscoll et al, 1991; Castranova et al, 2002). Several cytokines involved in lung inflammation, such as TNF$\alpha$ and NFкB interfered with CYP1A1 induction (Tian et al, 1999; Ke et al, 2001; Paton and Renton, 1998). Experiments by Porter et al (2001), showed increases in both TNF $\alpha$ and NFKB in alveolar lavage fluid in rats exposed to silica. NFKB was shown by Tian et al (1999) to interact with the Ah receptor. This interaction was a possible reason for the CYP1A1 inhibition by cytokines. The binding to the XRE by the AhR and ARNT produced increased histone acetylation, an important activator of gene transcription (Ke et al, 2001). TNF- $\alpha$ treatment inhibited this acetylation and inactivated the CYP1A1 promoter, thereby inhibiting CYP1A1 induction (Ke et al, 2001). Cytokines like TNF- $\alpha$ are released in response to inflammatory injuries such as those caused by exposure to silica could possibly explain the decrease in CYP1A1 activity and expression in rats exposed to inducers of CYP1A1 and silica. Our studies showed that down regulation of CYP1A1 expression and activity occurred in vivo, in the rat lung after exposure to silica, a known inducer of inflammation. We confirmed inflammation by histopathology in our study 
Future studies might include extending the time period after intratracheal exposure. The animals in these studies were sacrificed 14 days after receiving a bolus intratracheal instillation of silica. It would be interesting to see if the significant changes found in the proximal alveolar region would still be present at 4 weeks or more following instillation. Another consideration to explore would be to administer the silica via inhalation exposure. Inhalation is considered a more natural method of exposure but costs and time would increase. Since inflammation was observed in our study and has also been demonstrated following inhalation exposures (Driscoll et al, 1991, Castranova et al, 2002, Porter et al, 2001, Castranova et al, 1996 ) the acute effects of silica on down regulation of CYP1A1 expression are likely to be unaffected by the method of exposure.

Exposure to 5 milligrams of silica was sufficient to inhibit CYP1A1 or CYP2B1 expression and activity. Histopathological changes associated with silica exposure (alveolitis, alveolar type II cell hyperplasia and hypertrophy, and lipoproteinosis) were also fully manifested in the lungs of rats at exposures of $5 \mathrm{mg}$ silica. Perhaps exposing the animals to even smaller amounts of silica or allowing for larger increases between doses (i.e., 5, 25, and $50 \mathrm{mg}$ treatments) would show a dose response effect. In our study, histopathologic manifestations of inflammation were also unaffected by the dose at this time point. Thus, doses or time points that changed inflammation would be more revealing in evaluating the relationship between silica-induced inflammation and downregulation of CYP1A1 activity and expression. 


\section{Conclusions}

- Xenobiotic metabolism is altered by silica exposure and is localized to a common site for deposition of silica and other respirable particles, the proximal alveolar duct region.

- These finding suggest that silica exposure modifies carcinogenic effects of PAHs, such as these in cigarette smoke.

- The proximal alveolar region is very important for inhaled carcinogens.

- Silica exposures of 5, 10, or 20 mgs each significantly decreased CYP1A1 and CYP2B1 activity in NF-exposed rats, but a dose response relationship was not detected. 


\section{Bibliography}

- Alexandrov, K., Cascorbi, I., Rojas, M., Bouvier, G., Kriek, E., and Bartsch, H. 2002. CYP1A1 and GSTM1 genotypes affect benzo[a]pyrene DNA adducts in smokers lung: comparison with aromatic/hydrophobic adduct formation.

Carcinogenesis. 23(12):1969-1977.

- Bartsch, H., Castegnaro, M., Rojas, M., Camus, A.M., Alexandrov, K., and Lang, M. 1992. Expression of pulmonary cytochrome P4501A1 and carcinogen DNA adduct formation in high risk subjects for tobacco-related lung cancer. Toxicology Letters. 64/65:477-483.

- Bartsch, H., Rojas, M., Nair, U., Nair, J., and Alexandrov, K. 1999. Genetic cancer susceptibility and DNA adducts: Studies in smokers, tobacco chewers, and coke oven workers. Cancer Detection and Prevention. 23(6):445-453.

- Brain, J.D., Knudson, D.E., Sorokin, S. P., and Davis, M. A. 1976. Pulmonary distribution of particles given by intratracheal instillation or by aerosol inhalation. Environ. Res. 11:13-33.

- Burke, D.M., and Mayer, R.T. 1974. Ethoxyresorufin: direct fluorimetric assay of a microsomal 0-dealkylation which is preferntially inducible by 3methylcholanthrene. Drug Metabolism and Disposition. 2(6):583-588.

- Burke, D.M., Thompson, S., Elcombe, C.R., Halpert, J., Haaparanta, T., and Mayer, R.T. 1985. Ethoxy-, pentoxy- and benzyloxyphenoxazones and homologues to distinguish between different induced cytochromes p-450. Biochemical Pharmacology. 34(18):3337-3345.

- Castranova, V., Rabovsky, J., Tucker, J.H., and Miles, P.R. 1988. The alveolar type II epithelial cell: a multifunctional pneumocyte. Toxicology and Applied Pharmacology. 93:472-483.

- Castranova, V. 1994. Generation of oxygen radicals and mechanisms of injury prevention. Environmental Health Perspectives. 102(Supplement 10):65-68.

- Castranova, V. 2000. From coal mine dust to quartz: mechanisms of pulmonary pathogenicity. Inhalation Toxicology. 12(Supplement 3):7-14.

- Castranova, V., Porter, D., Millecchia, L., Ma, J.Y.C., Hubbs, A.F., and Teass, A. 2002. Effect of inhaled crystalline silica in a rat model: time course of pulmonary reactions. Molecular and Cellular Biochemistry. 234/235:177-184.

- Cocco, P., Rice, C.H., Chen, J.Q., McCawley, M.A., McLaughlin, J.K., and Dosemeci, M. 2001. Lung cancer risk, silica exposure, and silicosis in Chinese 
mines and pottery factories: the modifying role of other workplace lung carcinogens. American Journal of Industrial Medicine. 40:674-682.

- Daly, A., Fairbrother, K.S., and Smart, J. 1998. Recent advances in understanding the molecular basis of polymorphisms in genes encoding cytochrome P450 enzymes. Toxicology Letters. 102-103:143-147.

- Dethloff, L.A., Gilmore, L.B., Gladen, B.C., George, G., Chhabra, R.S., and Hook, G.E.R. 1986. Effects of silica on the composition of the pulmonary extracellular lining. Toxicology and Applied Pharmacology. 84:66-83.

- Devereux, T. 1984. Alveolar type II and clara cells: isolation and xenobiotic metabolism. Environmental Health Perspectives. 56:95-101.

- Department of Health and Human Services, Center for Disease Control and Prevention, National Institute for Occupational Safety and Health. 2002. Health Effects of Occupational Exposure to Respirable Crystalline Silica. NIOSH Hazard Review.

- Driscoll, K.E., Maurer, J.K., Lindenschmidt, R.C., Romberger, D., Rennard, S.I., and Crosby, L. 1990. Respiratory tract responses to dust: relationships between dust burden, lung injury, alveolar macrophage fibronectin release, and the development of pulmonary fibrosis. Toxicology and Applied Pharmacology. 106:88-101.

- Driscoll, K.E., Lindenschmidt, R.C., Maurer, J.K., Perkins, L., Perkins, M., and Higgins, J. 1991. Pulmonary response to inhaled silica or titanium dioxide. Toxicology and Applied Pharmacology. 111:201-210.

- Driscoll, K.E., Costa, D. L., Hatch, G., Henderson, R., Oberdörster, G., Salem, H., and Schlesinger, R. B. 2000. Intratracheal instillation as an exposure technique for the evaluation of respiratory tract toxicity: uses and limitations. Toxicological Sciences. 55:24-35.

- Estabrook, R.W. 1998. The role of methods in the discovery of the cytochromes P450. Methods in Molecular Biology. Cytochrome P450 Protocols (Eds. I.R. Phillips and E.A. Shephard) Humana Press, Totowa, NJ, 1-13.

- Ferin, J., and Feldstein, M. 1978. Pulmonary clearance and hilar lymph node content in rats after particle exposure. Environ. Res. 16:342-352.

- Fubini, B., and Hubbard, A. 2003. Serial review: Role of reactive oxygen and nitrogen species (ROS/RNS) in lung injury and disease. Free Radical Biology and Medicine. 34(12):1507-1516. 
- Ghanem, M.M., Porter, D., Battelli, L.A., Vallyathan, V., Kashon, M.L., Ma, J.Y., Barger, M.W., Nath, J., Castranova, V., and Hubbs, A.F. 2004. Respirable coal dust particles modify cytochrome P4501A1 (CYP1A1) expression in rat alveolar cells. Am. J. Respir. Cell Mol. Biol. 31:171-183.

- Graham, W.G.B., Costello, J., and Vacek, P. M. 2004. Vermont granite mortality study: an update with an emphasis on lung cancer. JOEM. 46(5):459-466.

- Guengerich, F.P., and Shimada, T. 1998. Activation of procarcinogens by human cytochrome P450 enzymes. In Mutation Research. Vol. 400. 201-213.

- Guengerich, F.P. 2001. Forging the links between metabolism and carcinogenesis. Mutation Research. 488:195-209.

- Hankinson, O. 1995. The aryl hydrocarbon receptor complex. Annu. Rev. Pharmacol. Toxicol. 35:307-340.

- Hasler, J.A., Estabrook, R., Murray, M., Pikuleva, I., Waterman, M., Capdevila, J., Holla, V., Helvig, C., Falck, J., Farrell, G., Kaminsky L.S., Spivak, S., Boiter, E., and Beaune, P. 1999. Human cytochromes P450. Molecular aspects of medicine. 20:1-137.

- Henderson, R.F., Driscoll, K.E., Harkema, J.R., Lindenschmidt, R.C., Chang, I.Y., Maples, K.R., and Barr, E.B. 1995. A comparison of the inflammatory response of the lung to inhaled versus instilled particles in F344 rats. Fundamental and Applied Toxicology. 24:183-197.

- Hubbs, A.F., Castranova, V., Ma, J.Y.C., Frazer, D.G., Siegel, P.D., Ducatman, B.S., Grote, A., Schwegler-Berry, D., Robinson, V.A., Van Dyke, C., Barger, M., Xiang, J., and Parker, J. 1997. Acute lung injury induced by a commercial leather conditioner. Toxicology and Applied Pharmacology. 143:37-46.

- IARC (International Agency for Research on Cancer). IARC Monograph on the evaluation of carcinogenic risk of chemicals to humans. Silica, some silicates, coal dust and para-aramid fibrils. Vol. 68. Lyon: International Agency for Research on Cancer, 1997.

- Jackson, J.H. 1994. Potential molecular mechanisms of oxidant-induced carcinogenesis. Environmental Health Perspectives. 102(Supplement 10):155158.

- Johnson, G.D., Davidson, R.S., McNamee, K.C., Russell, G., Goodwin, D., and Holborow, E.J. 1982. Fading of immunofluorescence during microscopy: a study of the phenomenon and its remedy. Journal of Immunological Methods. 55:231242. 
- Ke, S., Rabson, A.B., Germino, J.F., Gallo, M.A., and Tian, Y. 2001. Mechanism of suppression of cytochrome P-450 1A1 expression by tumor necrosis factor- $\alpha$ and lipopolysaccharide. The Journal of Biological Chemistry. 276(43):3963839644.

- Kellerman, G., Shaw, C.R., and Luyten-Kellerman, M. 1973. Aryl hydrocarbon hydroxylase inducibility and bronchogenic carcinoma. New England Journal of Medicine. 289:934-937.

- Kondraganti, S.R., Fernandez-Salguero, P., Gonzalez, F.J., Ramos, K.S., Jiang, W., and Moorthy, B. 2003. Polycyclic aromatic hydrocarbon-inducible dna adducts: evidence by ${ }^{32} \mathrm{P}$-postlabeling and use of knockout mice for $\mathrm{AH}$ receptorindependent mechanisms of metabolic activation in vivo. Int. J. Cancer. 103:5-11.

- Levy, R.D., Hubbs, A.F., Ducatman, B.S., Singh, G., Vallyathan, V., Bowman, L.L., and Miles, P.R. 1997. Metabolic functions of alveolar type II cells in acute silicosis. The Toxicologist. 36:74.

- Ma, J.Y.C., Yang, H.M., Barger, M., Siegel, P.D., Zhong, B.Z., Kriech, A.J., and Castranova, V. 2002. Alteration of pulmonary cytochrome P-450 system: effect of asphalt fume condensate exposure. Journal of Toxicology and Environmental Health, Part A. 65:1247-1260.

- Ma, J.Y.C., Rengasamy, A., Frazer, D., Barger, M., Hubbs, A.F., Battelli, L., Tomblyn, S., Stone, S., and Castranova, V. 2003. Inhalation exposure of rats to asphalt fumes generated at paving temperatures alters pulmonary xenobiotic metabolism without lung injury. Environmental Health Perspectives. 111(9):1215-1221.

- Masson, P.J. 1929. Trichrome stainings and their preliminary technique. J. of Tech. Meth. 12:75-90.

- $\quad$ Miles, P.R., Bowman, L., and Miller, M.R. 1993. Alterations in the pulmonary microsomal cytochrome P-450 system after exposure of rats to silica. Am.J. Respir. Cell Mol. Biol. 8:597-604.

- Miles, P.R., Bowman, L., Jones, W.G., Berry, D.S., and Vallyathan, V. 1994. Changes in alveolar lavage materials and lung microsomal xenobiotic metabolism following exposures to $\mathrm{HCl}$-washed or unwashed crystalline silica. Toxicology and Applied Pharmacology. 129:235-242.

- Miller, B.E., Dethloff, L.A., and Hook, G.E.R. 1986. Silica-induced hypertrophy of type II cells in the lungs of rats. Laboratory Investigations. 55(2):153-163. 
- Miller, B.E., Dethloff, L.A., Gladen, B.C., and Hook, G.E.R. 1987. Progression of type II cell hypertrophy and hyperplasia during silica-induced pulmonary inflammation. Laboratory Investigations. 57(5):546-554.

- Miller, B.E., Chapin, R.E., Pinkerton, K.E., Gilmore, L.B., Maronpot, R.R., and Hook, G.E.R. 1987. Quantitation of silica induced type II cell hyperplasia by using alkaline phosphatase histochemistry in glycol methacrylate embedded lung. Experimental Lung Research. 12:135-148.

- Miller, B.E., and Hook, G.E.R. 1990. Hypertrophy and hyperplasia of alveolar type II cells in response to silica and other pulmonary toxicants. Environmental Health Perspectives. 85:15-23.

- Morgan, E.T. 2001. Regulation of cytochrome P450 by inflammatory mediators: why and how? Drug Metabolism and Disposition. 29(3):207-212.

- Mucci, L.A., Wedren, S., Tamimi, R.M., Trichopoulos, D., and Adami, H.-O. 2001. The role of gene-environment interaction in the aetiology of human cancer: examples from cancers of the large bowel, lung and breast. Journal of Internal Medicine. 249:477-493.

- Oberdrster, G. 1995. Lung particle overload: implications for occupational exposures to particles. Regulatory Toxicology and Pharmacology. 27:123-135.

- Oberdörster, G. 1997. Pulmonary carcinogenicity of inhaled particles and the maximum tolerated dose. Environmental Health Perspectives. 105(Supplement 5):1347-1356.

- Omiecinski, C.J., Remmel, R.P., and Hosagrahara, V.P. 1999. Concise review of the cytochrome P450s and their roles in toxicology. Toxicological Sciences. 48:151-156.

- Omura, T. 1999. Forty Years of Cytochrome P450. Biochemical and Biophysical Research Communications. 266:690-698.

- Osier, M., Baggs, R. B., and Oberdörster, G. 1997. Intratracheal instillation versus intratracheal inhalation: influence of cytokines on inflammatory response. Environmental Health Perspectives. 105(Supplement 5):1265-1271.

- Osier, M., and Oberdörster, G. 1997. Intratracheal inhalation vs intratracheal instillation: differences in particle effects. Fundamental and Applied Toxicology. 40:220-227.

- Pairon, J.C., Brochard, P., Jaurand, M.C., and Bignon, J. 1991. Silica and lung cancer: a controversial issue. Eur. Respir. J. 4:730-744. 
- Participants, International Life Sciences Institute Risk Science Institute Workshop. 2000. The relevance of the rat lung response to particle overload for human risk assessment: a workshop consensus report. Inhalation Toxicology. 12:1-17.

- Paton, T.E., and Renton, K.W. 1998. Cytokine-mediated down-regulation of CYP1A1 in Hepa1 cells. Biochemical Pharmacology. 55:1791-1796.

- Perera, F. 1997. Environment and Cancer: who are susceptible? Science. 278:1068-1073.

- Philpot, R.M., and Smith, B.R. 1984. Role of cytochrome P-450 and related enzymes in the pulmonary metabolism of xenobiotics. Environmental Health Perspectives. 55:359-367.

- Porter, D.W., Ramsey, D., Hubbs, A.F., Battelli, L., Ma, J., Barger, M., Landsittle, D., Robinson, V.A., McLaurin, J., Kahn, A., Jones, W., Teass, A., and Castranova, V. 2001. Time course of pulmonary response of rats to inhalation of crystalline silica: histological results and biochemical indices of damage, lipidosis, and fibrosis. Journal of Environmental Pathology, Toxicology, and Oncology. 20(Supplement 1):1-14.

- Schlage, W.K., Bulles, H., Friedrichs, D., Kuhn, M., and Teredesai, A.,. 1998. Cytokeratin expression patterns in the rat respiratory tract as markers of epithelial differentiation in inhalation toxicology. I. determination of normal cytokeratin expression patterns in nose, larynx, trachea and lung. Toxicologic Pathology. 26(3):324-343.

- Shi, S., Key, M.E., and Kalra, K.L. 1991. Antigen retrieval in formalin-fixed, paraffin-embedded tissues: an enhancement method for immunohistochemical staining based on microwave oven heating of tissue sections. The Journal of Histochemistry and Cytochemistry. 39(6):741-748.

- Smith, G.B.J., Harper, P.A., Wong, J.M.Y., Lam, M.S.M., Reid, K.R., Petsikas, D., and Massey, T.E. 2001. Human lung microsomal cytochrome P4501A1 (CYP1A1) activities: Impact of smoking status and cypla1, aryl hydrocarbon receptor, and glutathione s-transferase M1 genetic polymorphisms. Cancer Epidemiology, Biomarkers, and Prevention. 10:839-853.

- Stuart, B.O. 1976. Deposition and clearance of inhaled particles. Environmental Health Perspectives. 16:41-53.

- Thiedemann, K.-U., Nolte, Th., Rittinghause, S., and Ernst, H. 1991. Immunohistochemistry and morphology of particle-induced pulmonary lesion. Progress in Histo- and Cytochemistry. 23:200-212. 
- Tian, Y., Ke, S., Denison, M.S., Rabson, A.B., and Gallo, M.A. 1999. Ah receptor and NFkB interactions, a potential mechanism for dioxin toxicity. The Journal of Biological Chemistry. 274(1):510-515.

- Tian, Y., Rabson, A.B., and Gallo, M.A. 2002. Ah receptor and NFKB interactions: mechanisms and physiological implications. Chemico-Biological Interactions. 141(1-2):97-115.

- Timbrell, J.A. 1993. Biotransformation of Xenobiotics. General and Applied Toxicology Vol. 1 (B.Ballantyne, T. Marrs, and P. Turner Eds.) Macmillan Publishing Co., New York, 89-116.

- Tsuda, T., Mino, Y., Babazono, A., Shigemi, J., Otsu, T., Yamamoto, E., and Kanazawa, S. 2002. A case-control study of lung cancer in relation to silica exposure and silicosis in a rural area in Japan. Ann. Epidemiol. 12:288-294.

- Ullrich, V., and Weber, P. 1972. The o-dealkylation if 7-ethoxycoumarin by liver microsomes. Hoppe-Seyler's Z. Physiol. Chem. 353:1171-1177.

- Vallyathan, V., Shi, X., and Castranova, V. 1998. Reactive oxygen species: their relation to pneumoconiosis and carcinogenesis. Environmental Health Perspectives. 106(Supplement 5):1151-1155.

- Whitlock, J.P., Jr. 1999. Induction of cytochrome P4501A1. Anne. Rev. Pharmacol. Toxicol. 39:103-125.

- Whitlock, J.P., Jr., Okino, S.T., Dong, L., Ko, H.P., Clarke-Katzenberg, R., Ma, Q., and Li, H. 1996. Induction of cytochrome P4501A1: a model for analyzing mammalian gene transcription. FASEB J. 10:809-818. 


\section{VITA}

\section{Personal Information}

Name: $\quad$ Lori Ann Battelli

Address: $\quad 643$ Tyrone Avery Road

Morgantown, WV 26508

Phone: $\quad$ 304-594-2345

\section{Education}

B.S. Pennsylvania State University, Dairy and Animal Sciences 1991

RLAT American Association of Laboratory Animal Science, Technician 1997 Certification

M.S. West Virginia University, Genetics and Developmental Biology

\section{Professional Positions}

Research Biologist

1999 -

National Institute for Occupational Safety and Health, Health Effects

present

Laboratory Division, Pathology and Physiology Research Branch,

Morgantown, WV

Biological Laboratory Technician

$1996-$

National Institute for Occupational Safety and Health, Health Effects

Laboratory Division, Pathology and Physiology Research Branch,

Morgantown, WV

Necropsy Group Supervisor

$1992-$

MPI Research

1996

Mattawan, MI 49076

\section{Professional Societies}

Allegheny-Erie Society of Toxicology (AESOT)

Allegheny-Erie Society of Toxicology(AESOT), Counselor

1999 - present 2004

American Association for Laboratory Animal Science (AALAS)

Three Rivers Branch AALAS, Newsletter Editor

\section{Awards}

Charles C. Shepard Science Award Nominee, Outstanding Science Paper 